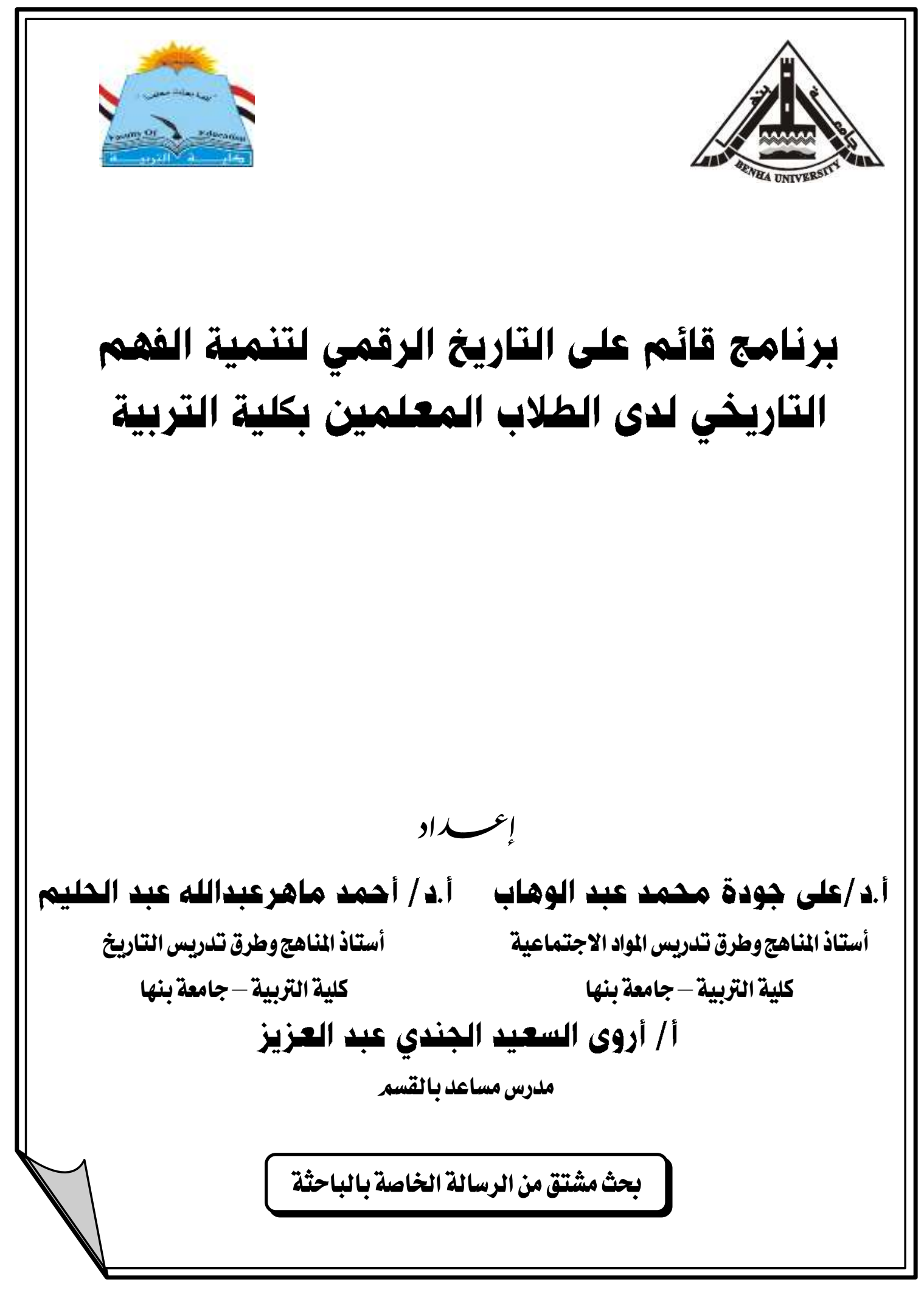




\section{برنامج قائم على التاريخ الرقمي لتنمية الفهم التاريخي لدى الطلاب المعلمين بكلية التربية}

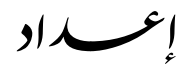

أ.د/على جودة محمد عبد الوهاب أ.د/ أحمد ماهرعبدالله عبد الحليم أحسيم

أستاذ المناهجوطرق تدريس التاريخ

كلية التربية- جامعة بنها
أستاذ المناهج وطرق تدريس المواد الاجتماعية

كلية التربية - جامعة بنها

أ أروى السعيد الجندي عبد العزيز

ملدرس مساعد بالقسه

أولاً: المقدمبسمسة والإحساس بالمشكلة:

لقد قادت التقنيات الرقمية إلى تطورات كبيرة فى جميع مجالات الحياة، حيث تعتبر الرقمنة هي الصفة الغالبة لعصرنا الحالي، وأدى التطور فى تكنولوجيا المعلومات والاتصالات إلى ما يسمى بالثورة الرقمية، ومن المتوقع أن يُحدث العصر الرقمي ثورة فى التعليم والتعلم،

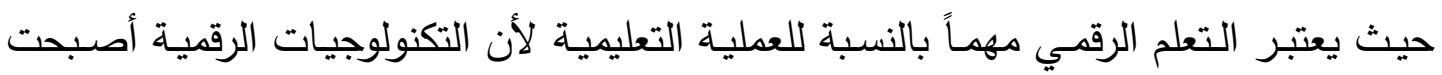
الوسيلة لإنتاج المعارف والتعبير عن الآراء والأفكار ويسرت الإستفادة من مختلف مصسادر

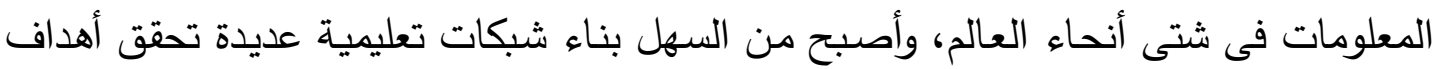
التعليم بسرعة وبأقل التكاليف، كما أمكن أيضاً تحقيق التكامل الإلكتروني بين برامج التعليم والتدريب على المستوى العالمي.

وهناك أسباب عدة دعت لاستخدام التكنولوجيا الرقمية فى التعليم منها شغف المتعلمين بها حيث أنها تزيد من دافعيتهم ومشاركتهم فى عملية التعليم والتعلم من خلال إكسابهم أربعة مفاتيح أساسية هى: التفاعل، اللعب، العمل، التعليم والتعلم، بهـا يؤدي إلى ارتفاع مستوى مهرى

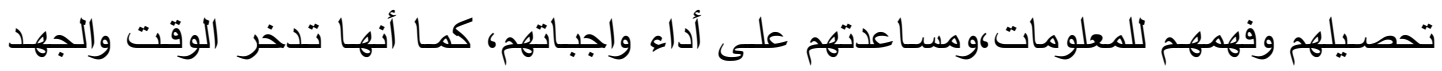
للمعلم، علاوة على أنها توفر النفقات على الددى الطويل.(السقا"دينا"، 1 ـ ب، . . 1 ) 
وقد أكد ذلك (Lee, Molebash,2004, 156) حيث يرى أن استخدام التكنولوجيا الرقمية فى العملية التعليمة تسمح بالتفاعل والإيجابية والمرونة من قبل المعلم والمتعلمين على السواء، فهى تختلف عن التعلم التقليدي أو غير الإكتروني. بـ

فالتاريخ الرقمي مفهوم جديد يصف عمليات استخدام دارسي التاريخ وطلابه للأدوات

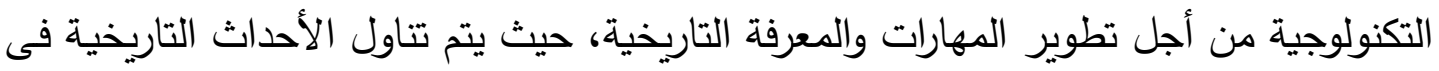
الماضي باستخدام عدد من النصوص والصور والمواد المعاد إنتاجها إلكترونيا، وكذلك الروايات أو التفسيرات أو القضايا التاريخية. (Lee, 2002, 505)

ومن بين ما يهدف إليه التاريخ الرقمي تتمية مهارات معلى التاريخ قبل الخدمة وفى أثنائها،

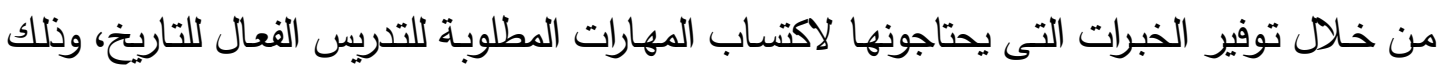

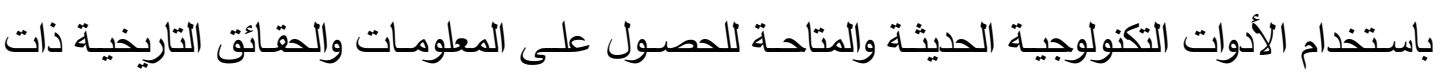
الأهمية القومية والإقليمية والمحلية وتحديد العلاقة بين هذه المعلومات وتقييم القيمة التاريخية لها، كما يهدف التاريخ الرقمي إلى إثرالك الطلاب في العطلية التعليمية من خلال أنثطة التسريس البنائية.

(Lee, Molebash,2014,169)

فالتاريخ الرقمي يقدم للتاريخ ما هو أكثر من الخدع المتقنه والأدوات المثيرة والنظرة

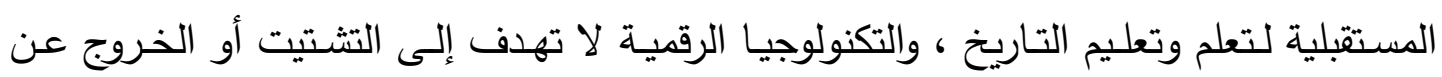

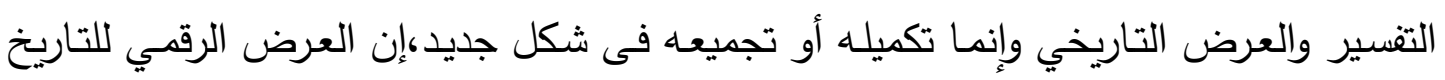

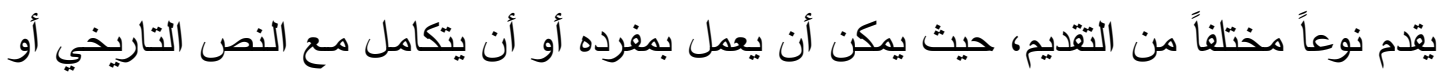
العرض المتحفي، كمـا أن التاريخ الرقمي قـادر على تقديم المعلومات بمـا يتوافق مـع تحليل

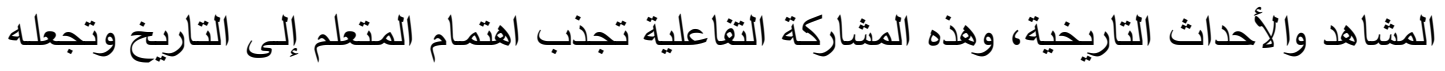

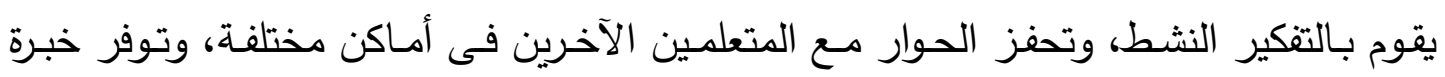
تفاعلية تدعو المتعلم إلى التجول والتنقل بطريقة منظمة، حيث أن تطبيقات التاريخ الرقمي تعزز مفهوم التجول من خلال منح المشارك معلومات أكثر عن الموقع التاريخى أو القضية التاريخية التى يتم عرضها وإعمال كل حواسه فى السياق التاريخي، كما يمكن عرض الصور والأشكال 
والخرائط، ووصف المواقع والأماكن التاريخية ، وإن القدرة على رؤية الموقع التاريخي والتفاعل

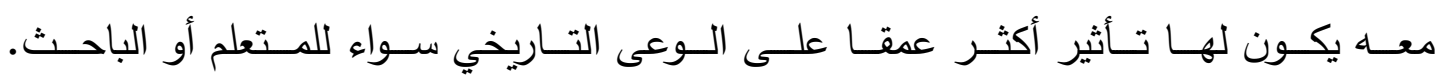
(Johenston, 2014,7,8)، ولذلك يتحدى التاريخ الرقمي النماذج التقليدية السائدة فى تعلم وتعليم التاريخ ، والفكر القائم على الاعتماد على الكتب والنص التاريخي المقروء فقط. وفى ظل هذا التغير السريع فى مجتمع المعلومات، أصبحت مادة التاريخ تواجه العديد

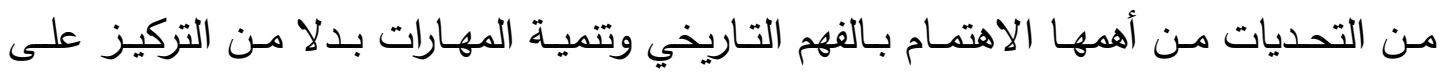

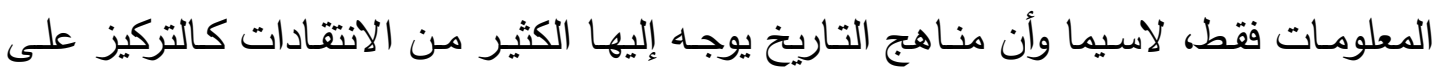

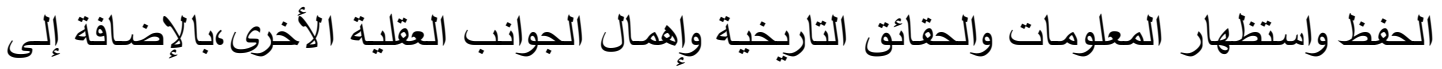
ذللك فإنها تقدم للمتعمين بصورة جافة على نحو قد يكون معوقاً للفهم التاريخي لهذه الأحداث ،

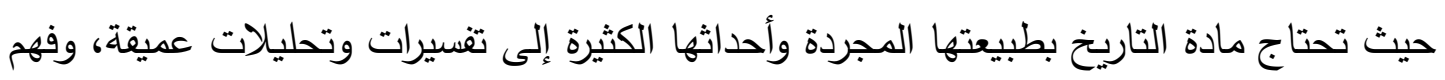

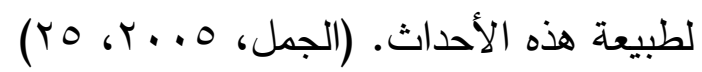
ويعد الفهم التاريخي من أهم الأهداف التى تسعى دراسة مادة التاريخ إلى تحقيقها، حيث

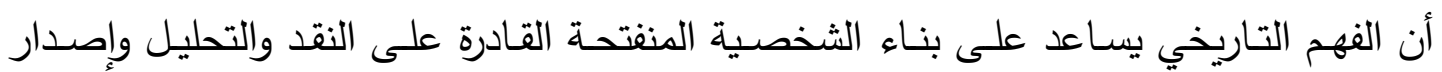
الأحكام وتقبل الرأي الآخر ، من خلال تقديم أسانيد وأدلة تاريخية، وكذلك يعمل على تفسير

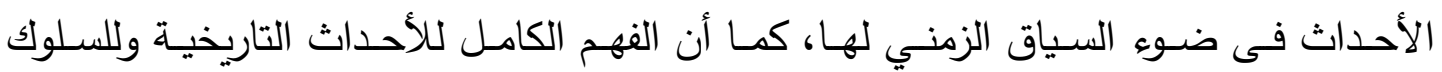

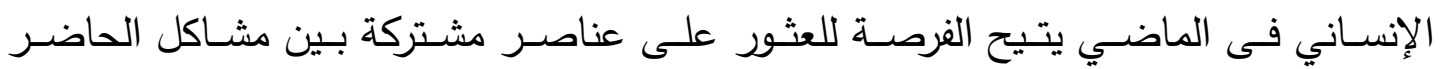

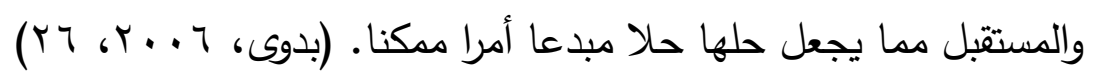

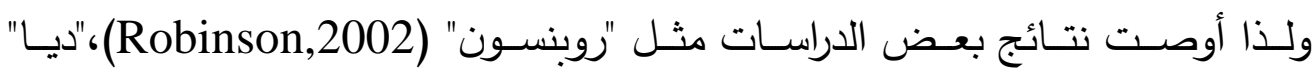
(Dia,2012) بضـرورة الاهتمـام بتتميـة الفهـم التـاريخي لـدى الطـلاب المعلمـين، واسـتخدام التكنولوجيا الحديثة فى تناول الموضوعات التاريخية، وجعل المتعلم الأساس فى متابعة الأحداث الجارية ونقدها وتفسيرها واستنتاج ما يترتب عليها بصورة جيدة.

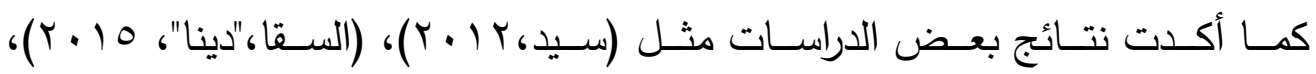

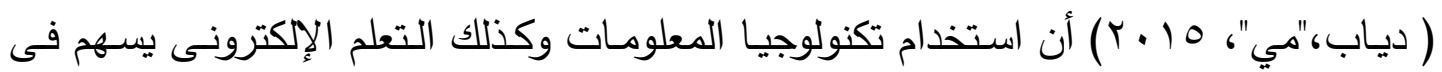
تتمية الفهم التاريخي فى المراحل التعليمية المختلفة. 
ولذا يمثل التاريخ الرقمي باعتباره اتجاهاً تكنولوجياً حديثاً مجالاً جديداً لفهم التاريخ،

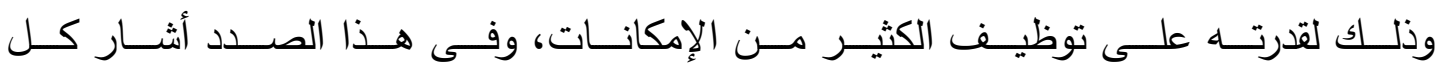

مـ(Calandra,Lee,2005,325) إلى أن التاريخ الرقمسي يسهـم فـى فهم الطـلاب لأحداث

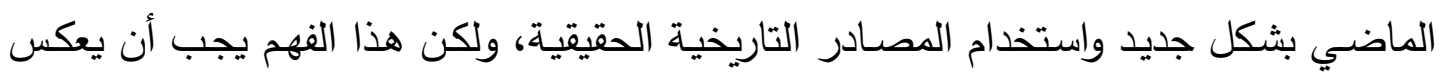
أيضاً المعرفة المتميزة والكلية والعمليات العلمية لاكتساب المعرفة، إن فهم الطلاب للتاريخ أو وله الماضي يجب أن يكون فى شكل تقسيرات جديدة أو مبتكرة ، وهذا الفهم يجب أن يوسع ويزيد من اهتمام الطلاب بالتاريخ، ولكي يتحقق ذلك لابد من إيجاد واقع يعيثه الطلاب لتمثيل هذا

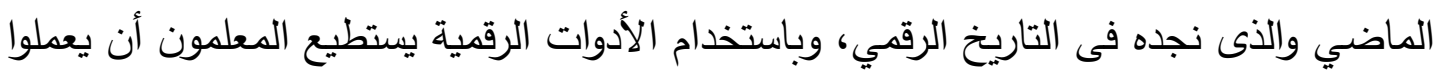

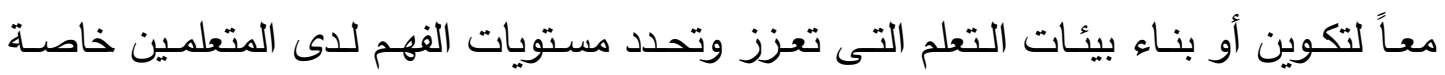

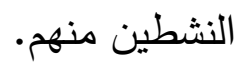

\section{الإحســاس بالمشكلة:}

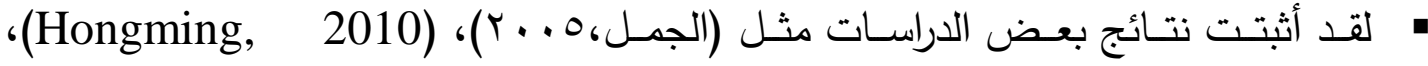

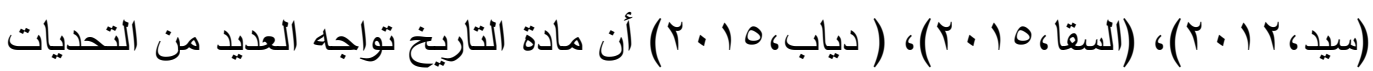

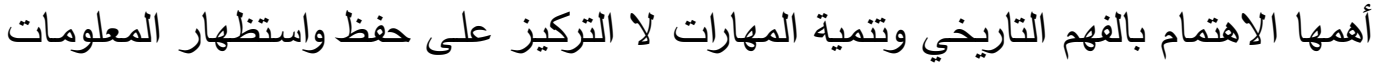

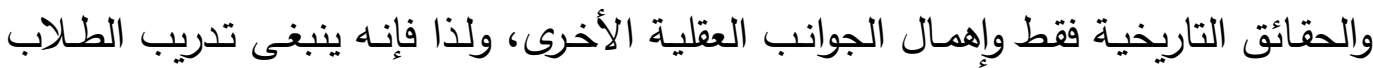
المعلمين تخصص التاريخ على مهارات التدريس الإبداعي وتتمية الفهم التاريخي لايهم.

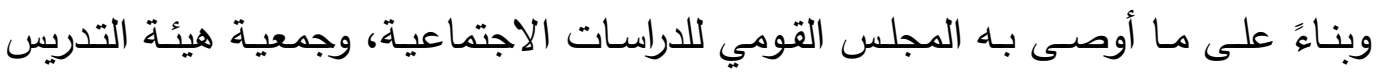
الجامعية (CUFA) بأهمية دمج التكنولوجيا فى برامج إعداد معلمي الدراسات الاجتماعية بشكل عام والتاريخ بشكل خاص وذلك لتمية الفهم التاريخي لديهم.

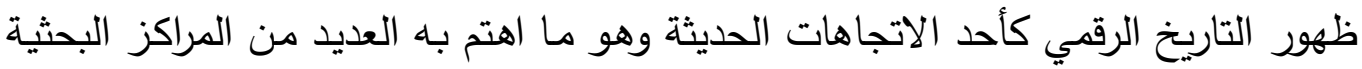

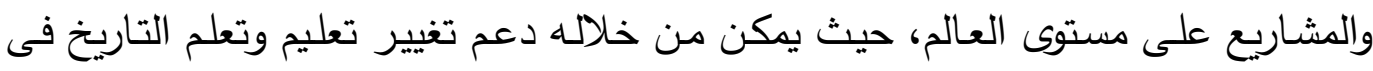

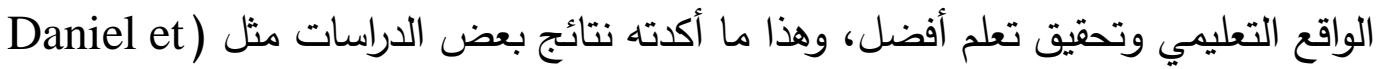
.(Johnston, 2014) ،(Lee \& Molebash, 2014) (al. ,2008 وانطلاقاً مما سبق يهدف هذا البحث إلى إعداد برنامج قائم على التاريخ الرقمي لتتمية الفهم التاريخي ومهارات التدريس الإبداعي لدى الطلاب المعلمين. 
تتحدد مشكلة البحث الحسالي فى تدني مستوى الفهم التاريخي للدى الطـلاب المعلدين وحاجاتهم إلى برامج تعليمية حديثة قد تسهم فى تتمية الفهم والتعمق فى المعلومات التاريخية لديهم. وللتصدى لهذه المثكلة يحاول البحث الحالي الإجابة عن الأسئلة الآتية: س ا : ما مهارات الفهم التاريخي المناسبة للطلاب المعلمين بشعبة التاريخ؟ س r: ما البرنامج القائم على التاريخ الرقمي لتدريس بعض الموضوعات التاريخية؟ سب: ما فاعلية البرنامج فى تتمية الفهم التاريخي لدى عينة من الطلاب المعلمين بثعبة التاريخ؟ ثالثاً: أهميسـة البحث: تتمثل أهمية هذا البحث فى: 1- الاستجابة للاتجاهات العالمية الحديثة فى توظيف التكنولوجيا واستخدام التاريخ الرقمي فى تلى تعليم وتعلم التاريخ، الأمر الذى قد يؤدي إلى تغيير الواقع التدريسي والتعليمي للتاريخ،

$$
\text { وتحقيق الكثير من الأهداف المرجوة. }
$$

ץ- تقديم نموذج لبرنامج قائم على التاريخ الرقمي، ما قد يسهم فى تنمية الفهم التاريخي لاى الى

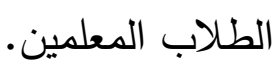
r-قد تثيد فى توجيه وتطوير برامج إعداد معلمي التاريخ بكلية التربية على ضوه استخدام

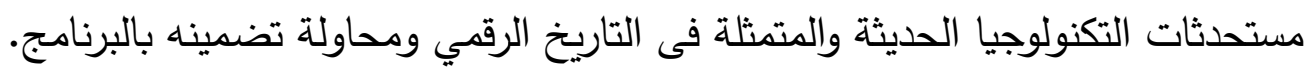
ع - قد تسهم فى فتح مجال جديد للبحث فى تعليم وتعلم التاريخ وذلك من خلال ما يتم التوصل

$$
\text { إليه من توصيات ومقترحات. }
$$

\section{يقتصر هذا البحث على الدود الآتية:}

1- بعض مهارات الفهم التاريخي المناسبة للطلاب المعلمين تخصص التاريخ، كما تحددها قائمة المهارات. بعض مهارت r- عينة من الطلاب المعلمين بثعبة التاريخ بالفرقة الثالثة بكلية التربية. r- موضوعات من التاريخ تتاسب طلاب العينة ويتم تحويلها إلى التاريخ رقمي. 
يعرفه "دانيال وآخرون" بأنه أحد الاتجاهات الحديثة فى مجال التاريخ والمرتبطة بقدرة التقنيات المتطورة على فهم وتفسير وتحليل أحداث الماضي، من خلال تحويله إلى مادة رقمية، أي أنها إطار تكنولوجي يسمح للمتعلمين بقراءة ومتابعة الأحداث والقضـايا التاريخية الكبرى.

(Daniel et al. ,2008,454)

ويثير "جونستون" إلى أن التاريخ الرقمي مجال حديث منطور يتقدم بالتوازى مـع أحدث

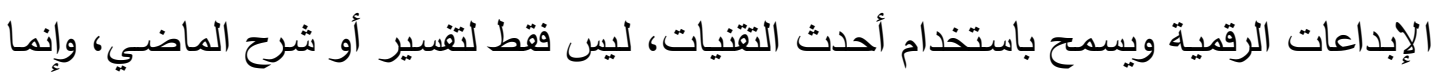

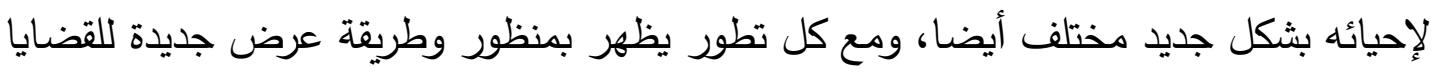
والأحداث التاريخية. (Johnston, 2014, 8) ويعرف التاريخ الرقمي فى إجرائياً فى البحث الحالي بأنها: مجال حديث متطور يسمح

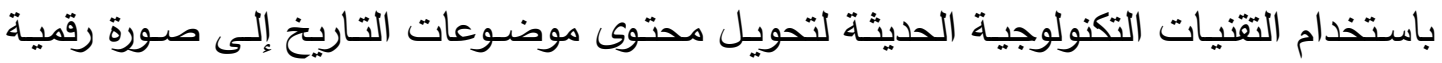

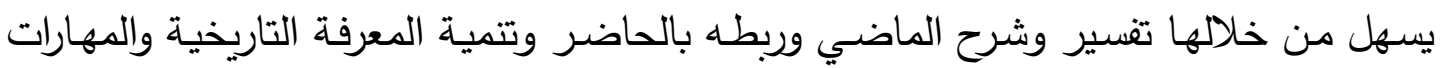

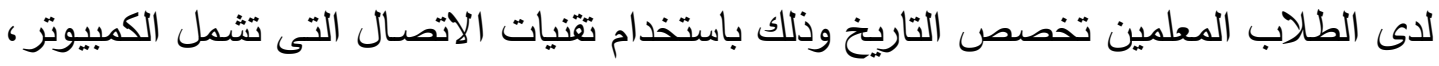
وشبكة الإنترنت، ونظم البرمجيات.

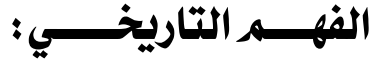

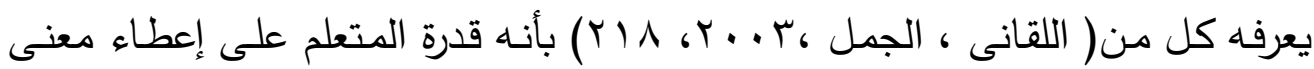
للموقف الذى يواجها، ويستدل عليه من مجموعة السلوكيات العقلية التى يظهرها تجاه الموقف، لتهن

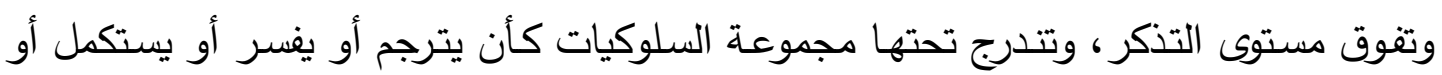

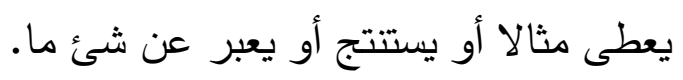

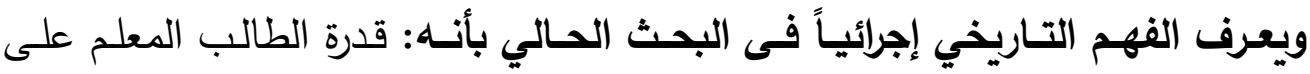
الترتيب الزمني للأحداث والقضايا التاريخية والربط بينها وتفسيرها، وتقصي الحقائق التاريخية باستخدام الأدلة والمصادر المتاحة، والقدرة على الاستتتاج واستخلاص الدروس المستفادة من الدراسة التاريخية، وذلك من خلال معايشة الموقف أو القضية التاريخية وتحليلها وفهم مغزاهـا

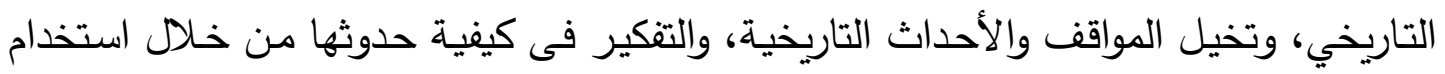
التاريخ الرقمي. 
ا- تحلديد مهارات الفهم التاريخي اللازمة للطلاب المعلمين بشعبة التاريخوذلك من خلال : • الاطلاع على الأدبيات التزبوية والدراسات والبحوث السابقة والتى تتاولت مهارات الفهم التاريخي.

$$
\text { • آراء الخبراء والمتخصصين فى طرائق تدريس التاريخ. }
$$

• التوصل إلى قائمة مبئية بمهارات الفهم التاريخي المناسبة للطلاب المعلمين بثعبة التاريخ. • عرض هذه القائمة على مجموعة من الخبراء والمتخصصين فى مجال المناهج وطرائق

$$
\text { التدريس تخصص التاريخ. }
$$

• تحديد قائمة نهائية لمهارات الفهم التاريخي بعد إجراء كافة التعديلات المطلوبة.

r- تصميه البر نامج المقترح القائم على التاريخ الرقمي وذلك من خلال :

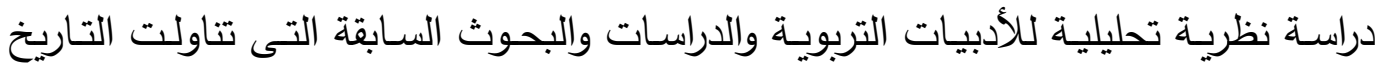
الرقمي فى مجال تعليم وتعلم التاريخ.

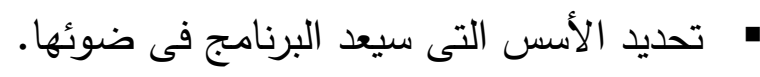

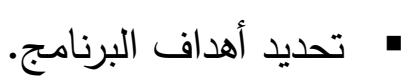
• اختيار بعض موضوعات التاريخ المناسبة (محتوى البرنامج). • تحويل الموضوعات التاريخية المختارة إلى صورة رقمية.

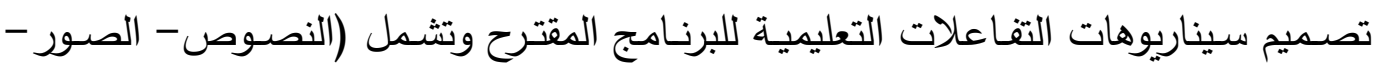
الرسومات- الروابط-المؤثرات الصـوتية والحركيـة-المتاحف الافتراضية- خرائط التراث

$$
\begin{aligned}
& \text { العالمي- الموسوعات الرقمية- أدوات web2). } \\
& \text { • تحديد إستراتيجيات وأساليب التعلم المناسبة. } \\
& \text { • تحديد أساليب التقويم المتبعة فى البرنامج. }
\end{aligned}
$$

ب- تحديد فاعلية البرنامج المقترح فى تنمية الفهم التاريخي للدى الطلاب المعلمين وذلك من خلال : • إعداد اختبار لقياس الفهم التاريخي لاى عينة من الطلاب المعلمين تخصص التاريخ. • اختيار عينة من الطلاب المعلمين تخصص التاريخ بالثرقة الثالثة. 
• تطبيق أداة البحث قبلياعلى عينة البحث.

- تطبيق البرنامج القائم على التاريخ الرقمي على الطلاب المعلمين -الفرقة الثالثة شعبة التاريخ- وذلك ضمن الساعة العملية لمادة طرق التدريس.

$$
\begin{aligned}
& \text { • تطبيق أداة البحث بعديا ورصد النتائج. } \\
& \text { • تحليل النتائج وتقسيرها. } \\
& \text { • تقديم التوصيات والمقترحات. }
\end{aligned}
$$

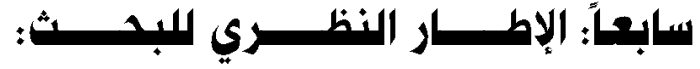

المحور الأول : التاريخ الرقمي:

ماهية التاريخ الرقمي وأهدافه:

فالتاريخ الرقمي كما يعرفه (Lee,2002,505) مفهوم جديد يصف عمليات استخدام

دارسى وطلاب التاريخ للأدوات التكنولوجية من أجل تطوير المعرفة التاريخية والمهارات اللازمة

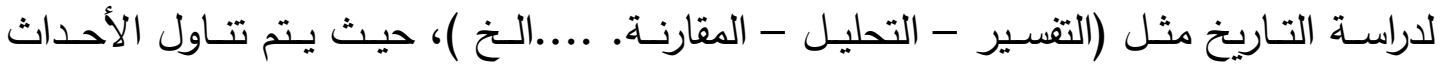
التاريخية فى الماضـى باستخدام عدد من النصوص الرئيسة والصور والمواد المعـاد إنتاجها الكترونيا، وكذلك الروايات أو التقسيرات أو القضايا التاريخية.

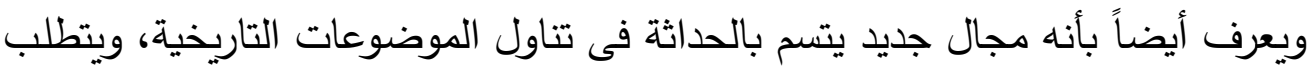

التعاون والتآلف بين المهتمين وطلاب ودارسي التاريخ ، وأنماط الدراسة والبحث في في القضايا

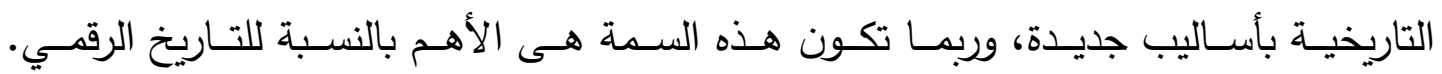

( Lee,Molebash,2014, 160)

ويمكن فهم التاريخ الرقمي بشكل عام كمدخل لبحث وتمثيل الماضي من خلال تقنيات

الاتصال التى تثمل الكمبيوتر وشبكة الانترنت ونظم البرمجيات ، فعلى أحد المستويات يعتبر

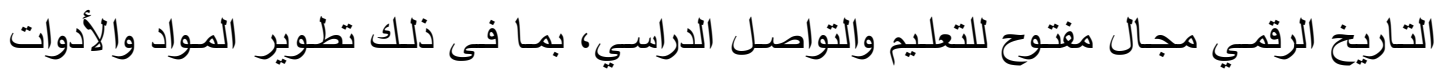
التعليمية الحديثة وجمع البيانات والمعلومات والحقائق التاريخية. ( Daniel et al,2008,554) ويعرف التاريخ الرقمى إجرائيا بأنه مجال حديث متطور يسمح باستخدام أحدث التقنيات

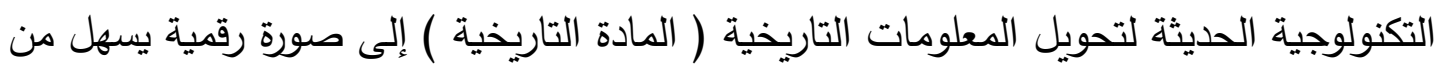
خلالها تفسير وشرح الماضى وربطه بالحاضر وتتمية المعرفة التاريخية والمهارات لدى الطلاب 
المعلمين تخصص تاريخ وذلك باستخدام تقنيات الاتصـال التى تثمل الكبيوتر ، وشبكة

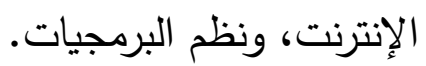

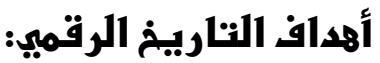

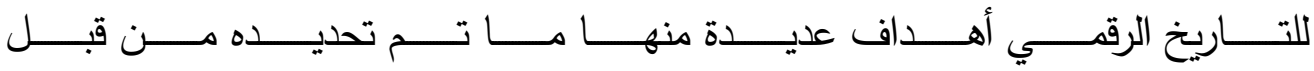

(Lee,Molebash,2004,154,156)، (Lee,Molebash,2014,169) حيث أنها تتمثل فى: تحسين قدرات معلمي التاريخ بصفة خاصة قبل الخدمة وأثنائها والمتعلقة بتدريس وتعلم

$$
\text { التاريخ من خلال التاريخ الرقمي. }
$$

" اكتساب الخبرات والمهارات المطلوبة للتريس الفعال للتاريخ. • استخدام الأدوات التكنولوجيـة والتقنيـات الحديثة والمتاحـة للحصول على المعلومـات والحقائق التاريخية ذات الأهمية القومية والإقليمية والمحلية. • إدرالك العلاقة بين الموضوعات التاريخية والربط بينها. • إصدار أحكام حول الأحداث التاريخية وإدراك القيمة الحقيقية لتعلم التاريخ. • إشراك الطلاب فى العملية التعليمية من خلال أنشطة التدريس البنائية. " تغيير الممارسات الحالية فى تدريس التاريخ بثكل جوهري. تدعيم استخدام التاريخ الرقمي من قبل الطلاب المعلمين أثناء إعدادهم لتدريس التاريخ

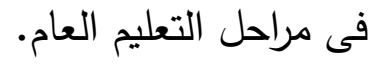

\section{مبادئ التناريخ الرقمي ومتطلباته:

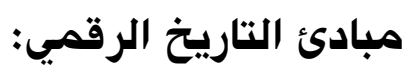

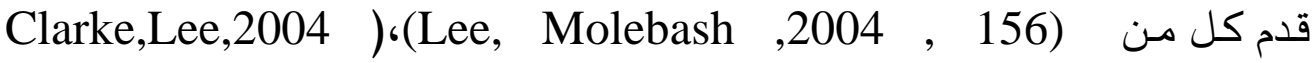

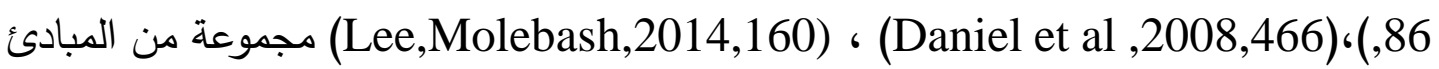
التى ينبغى مراعاتها عند استخدام التاريخ الرقمى منها:

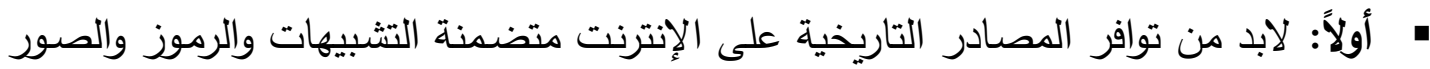

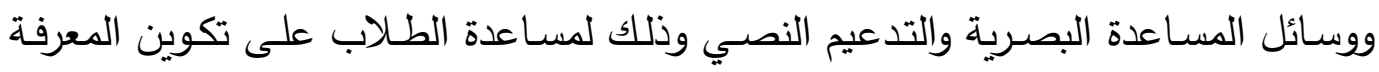

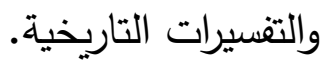


• • ثانياً: ينبغى توافر فرص المشاركة الإيجابية والتقسير من قبل المتعلمين بتوجيه من المعلم

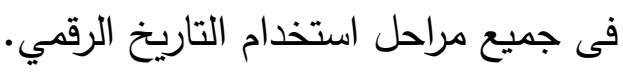

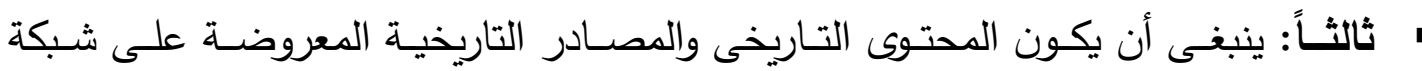
الانترنت لاخطية ويتصفوا بالمرونـة والتركيز على القضـايا الأساسية والحقائق التاريخيـة القابلة للتفسير والتحليل.

رابعـاً: يجب أن يتم فى إطـار اجتمـاعى و تعليمى هـادف و ذى معنى لتعزيز خبـرات المشاركة و النقد و الديمقراطية لاى المتعلمين.

\section{متطلبات التاريخ الرقمي:}

يحتاج التاريخ الرقمي إلى هيئات التدريس أو الأساتذة فى أقسام التاريخ وإلى الاتصـال

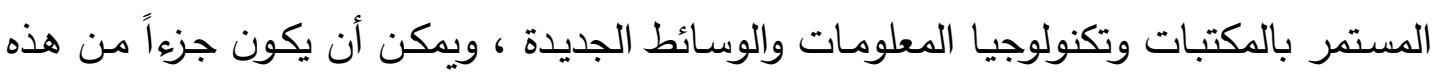

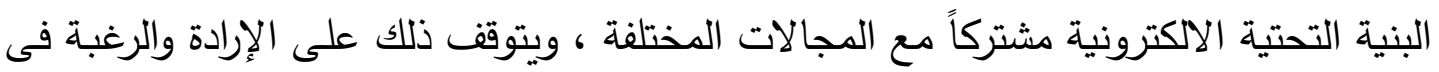
تجربة واستخدام الوسائط الجديدة وتوفير الموارد ، وقد لاتكون الموارد المالية هى العامل الحاسم فى النجاح المؤسسي فى مجال التاريخ الرقمي ، ولكن هناك حاجه للدمج بين الإرادة والرغبة الرانة

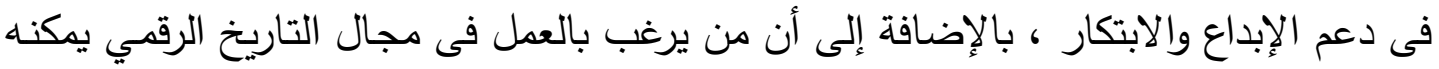

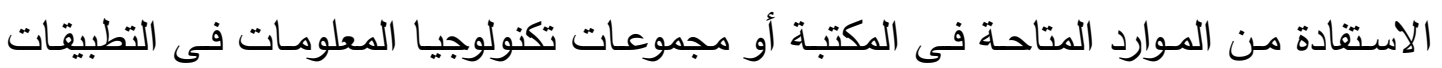

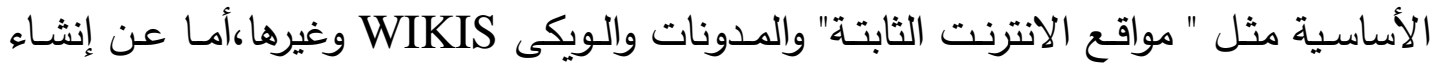

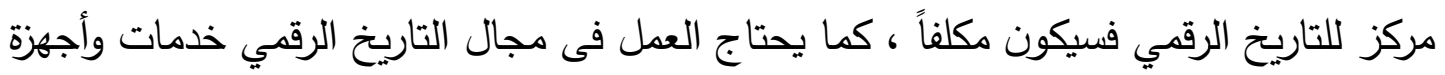

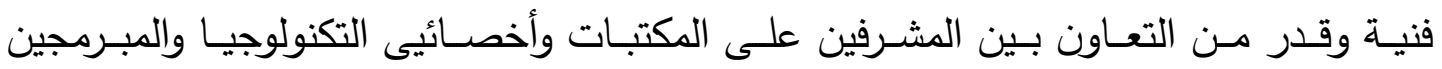

ومصدمي المعلومات والمؤرخين (Daniel et al., 2008,466,474)

\section{أهمية استخدام التاريخ الرقمي في دراسة التاريخ:}

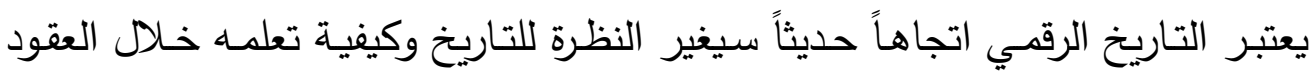

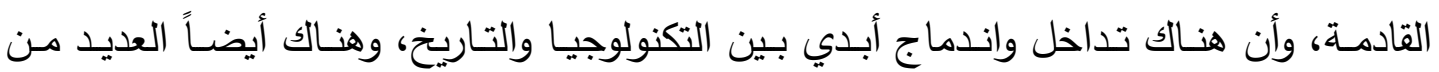

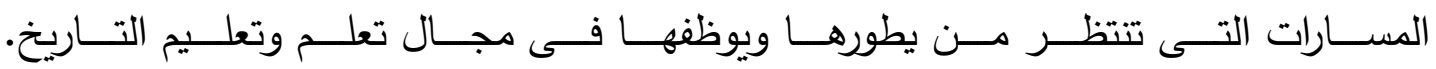
.(Johnston, 2014, 32,33) ويؤكد ذلك(Zahavi,2014,120) فيما عرضـه فى مؤتمرات وحوارات نقاشية، وورش عمل حـول التـاريخ الرقمي والتـاريخ الثـفهي، وذلك فـى مقاطعـة (فولتون) بولايـة جورجيـا 
الأمريكية، وتم التركيز على استخدام التقنيات الرقمية عبر شبكة الانترنت لتوفير المصادر التاريخية لجمهور واسع من الطلاب والباحثين.

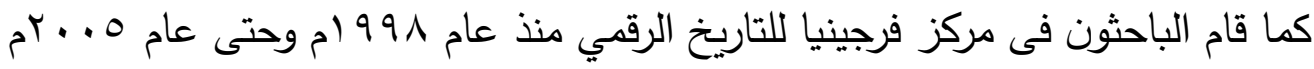

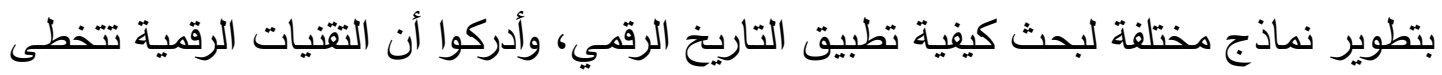

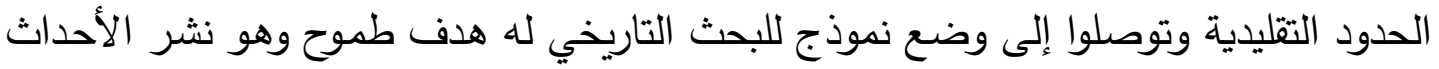

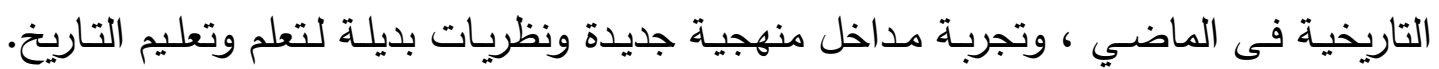
www.VCDH.com

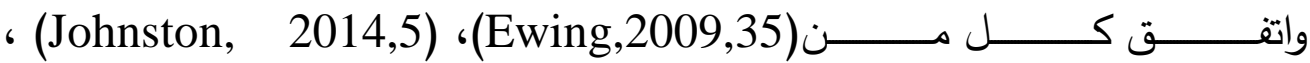
(Rosinbum,2016) ، (Lee,Molebash,2014,160)

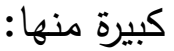
- توفير فرص الحصـول على المعلومـات التاريخية الحقيقيـة للماضـي ومعالجتها وتفسيرها والربط بينها ومقارنتها وتكوين الآراء أو وجهات النظر (إصدار الأحكام) بصددها.

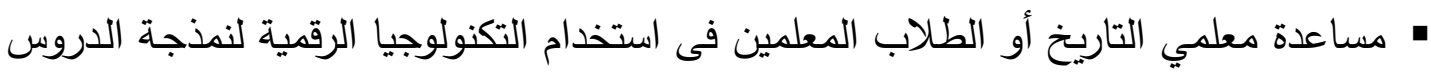
وتقديمها بشكل رقمى ، مع إشرالك المتعلمين فى ذلك وإكسابهم مهارات البحث التاريخي.

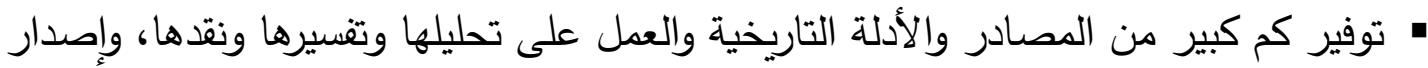

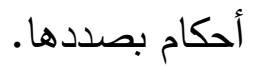

هإنشـاء إطـار مـن خـلال التكنولوجيـا يستطيع الطـلاب بواسطته قـراءة ومتابعـة الأحـداث والقضايا التاريخية الحديثة والمعاصرة. • تغيير الممارسات الحالية لتدريس التاريخ بشكل جوهرى، من خلال تقديم سمات لم يكن من الممكن تقديمها من خلال المواد المطبوعة. إثارة دافعية الطلاب، ومنحهم خبرة تعلم أكاديمية قوية فى نفس الوقت من خلال تثجيعهم على التفكير النشط. دور المعلم فى ظل استخدام التاريخ الرقمي:

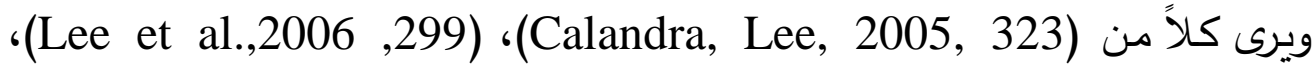

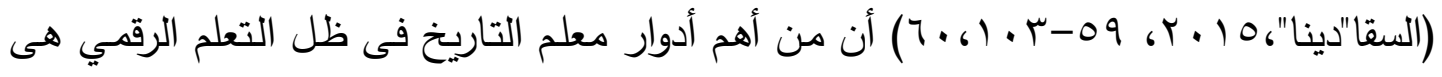

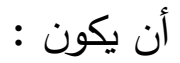


تسهيل عملية التعلم والتعامل بيسر مع الوسائل التكنولوجية وتشجيع المتعلمين على التعاون

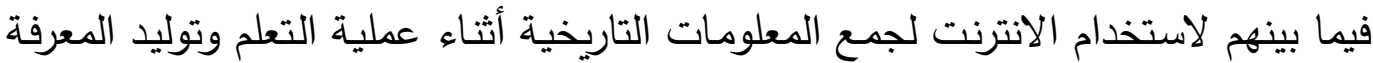
التاريخية الصحيحة لديهم.

إعداد المادة العلمية وبرمجتها واختيار الأساليب المناسبة لعرضها بجانب ذلك يقوم بتحديد المهام والأنثطة وأنماط المناقثة والتأكد من إتقان طلابه لمهارات التفاعل باستخدام أدوات ووسائل البيئة الرقمية. مناقش وموجه وقائد اجتماعي وإرشادي أثناء عملية التعلم ويكون دوره كبير عند تفاعله مع لعماني طلابه، وقيادته لعملية التعلم. ملاحظ ومقيم لعملية التعلم وأن يكون ملاحظاً لنقاط القوة والضعف فلى فلى تعلم طلابه. هصم للأنشطة التعليمية ومدرب طلابه على استخدام تكنولوجيا التعلم الرقمي. المتخصص فى المادة الأكاديمية فى ضوية التطبيقات التزبوية للتكنولوجيا الرقية فى التعليم. المر اكز والمشاريع العالميتة والمؤتمرات التى اهتمت بالتاريخ الرقمي:

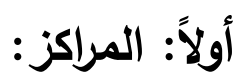

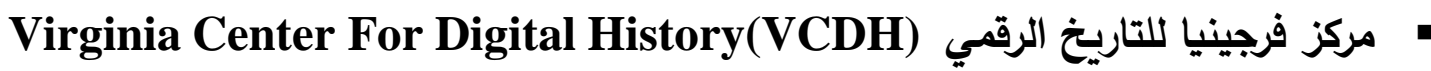
يعد هذا المركز أول المراكز عالمياً التى اهتمت بالتاريخ الرقمي، والذى تم تأسيسه عام

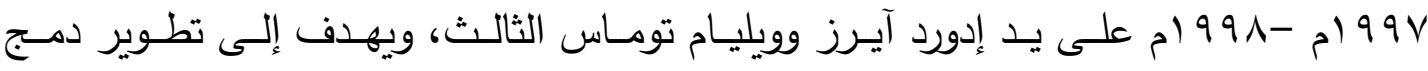

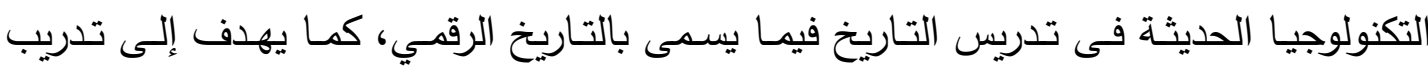

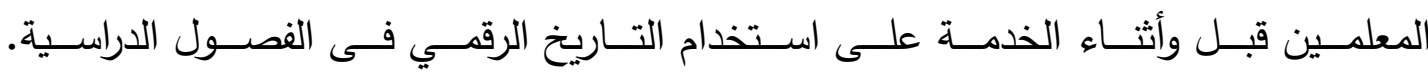

(www.vcdh.virginia.edu)

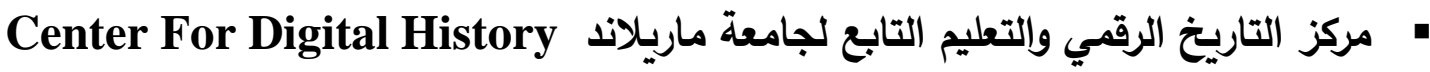
: \& Education(CDHE) at UMBC

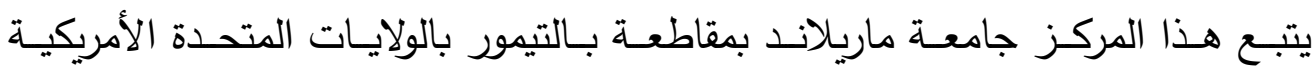

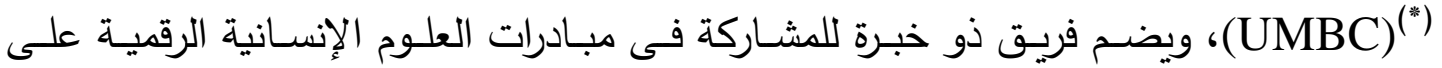

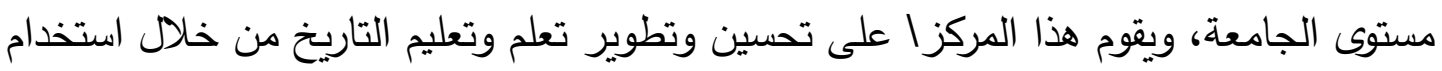

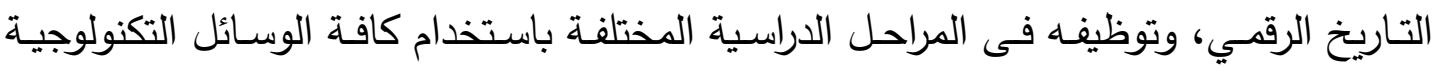
المكنة، وله مشروع عن التاريخ الرقمي الخاص به. www.cdhe.umbc.edu

${ }^{(*)}$ University Of Maryland,Baltimore Country 


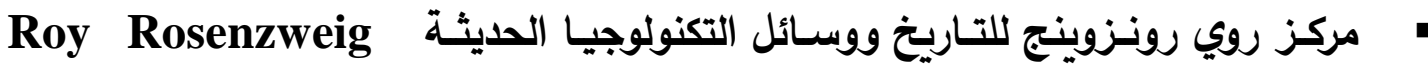
:Center For History \& New Media (RRCHNM)

أسس هذا المركز Roy Rosenzweig منذ عام ؟99 ام وتولى إدارته حتى وفاته

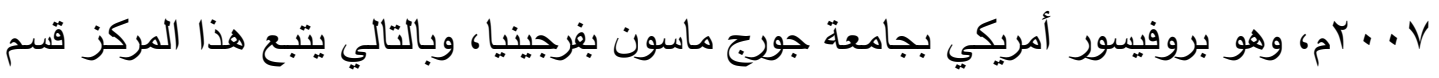

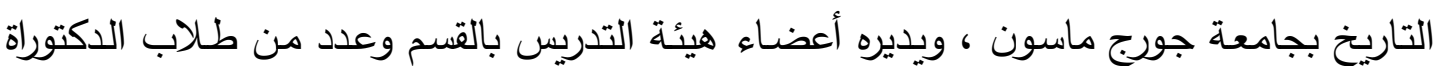
للعمل به كمساعدين مع إعطائهم فرصة تطبيق الجانب العملي الخاص بهم، يهدف إلى تطوير

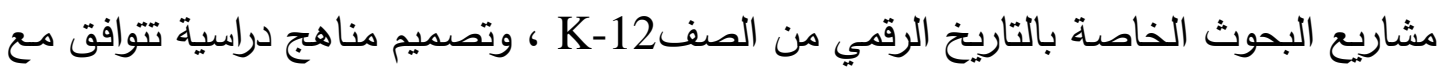
التاريخ الرقمي، تطوير مصادر التعلم عبر الإنترنت، ومجموعات العمل، والمتاحف التاريخية

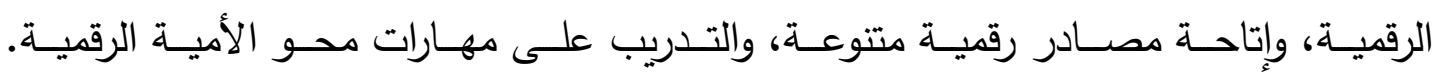

(www.rrchnm.org)

\section{• Digital History Centre مركز التاريخ الرقمي بجامعة إكسس :}

يتبع هذا المركز جامعة إكس البريطانية University Of Essex ويهدف إلى البى تعزيز

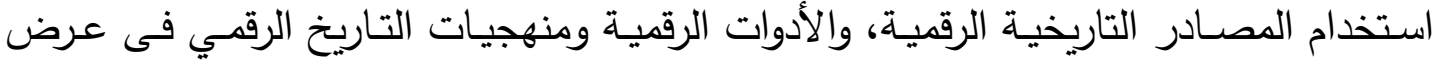

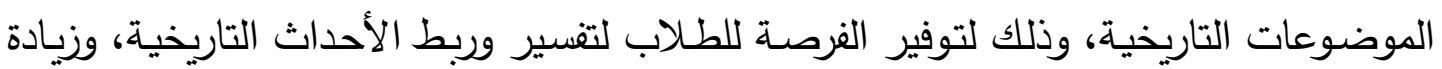
النقاش حول الموضوعات التاريخية. www.essex.ac.uk/history/research/digital-history.aspx ثانياً: المشاريع:

• مشروع التاريخ الرقمي التابع لجامعة نبرسكا بلنكولن DHProject:

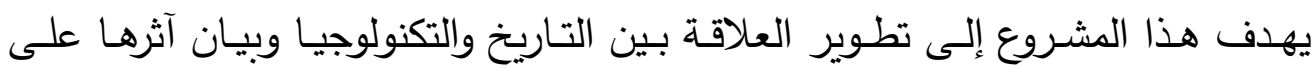
المتعلمين، ويقدم برامج ومقررات إلكترونيـة تتعلق بالتاريخ الرقمـي من خـلال دورات تدريبية للطلاب المعلمين بالجامعة وطلاب الدراسات العليا.www.digitalhistory.unl.edu Digital History \& Pedagogy مشـــ :Project(DHPP) أسس هذا المشروع أعضـاء هيئة التدريس والطلاب المعلمين فى كلية التربية فى محاولة لتوفير خبرات ذات معنى لتعليم الطلاب مادة التاريخ، ويهدف هذا المشروع إلى تمكين الطلاب

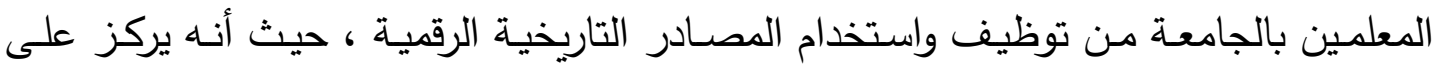

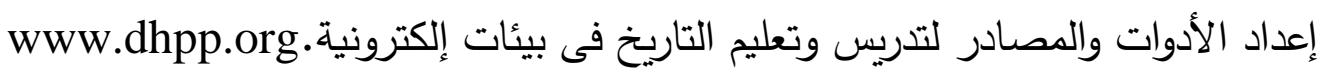


American Historical

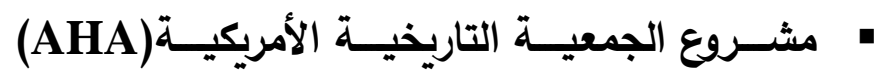

:Association

يعد هذا المشروع أحد المشاريع الهامه والحديثة والذى استهدف تطوير وحدات دراسية

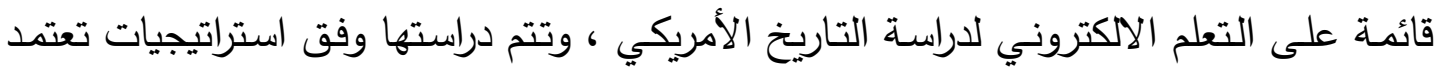

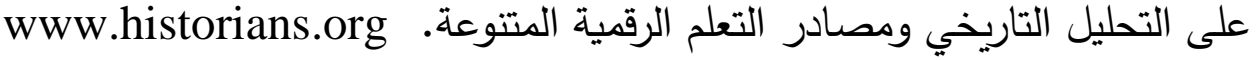

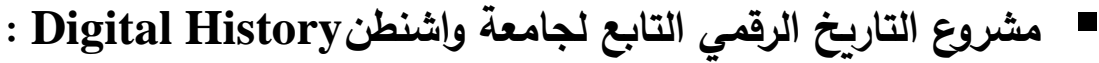

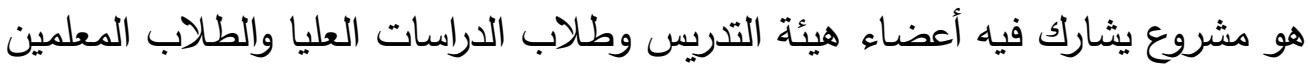
فى قسم التاريخ التابع لهذه الجامعة، وذلك لتحويل الموضوعات التاريخية المختلفة إلى الثكل الرقمي.

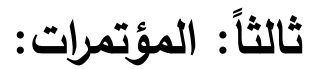

• المؤتمر الدولي للعلوم الأنسانية الرقمية والتاريخ الرقمي بمعهد التاريخ الألماني : Conference on Digital Humanities and Digital History at German Historical Institute(GHI). Washington

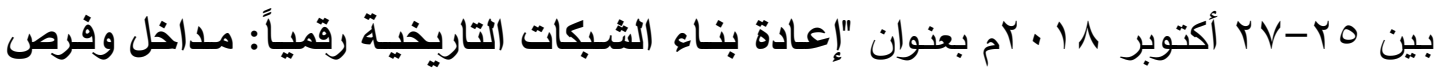

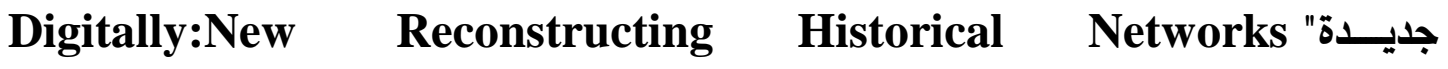
Approaches, Opportunities

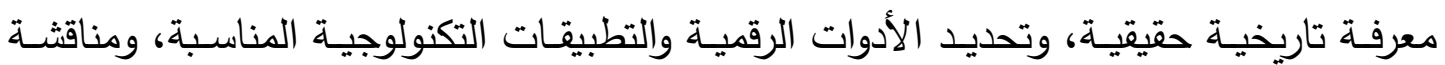

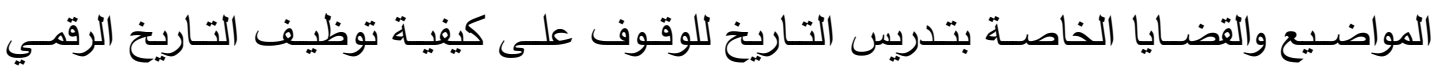
والثبكات الرقمية فى المناهج. • المؤتمر السادس لجمعية العلوم الإنسانية الرقمية فى الدول الناطقة بالألمانية Jahrestagung des Verbands Digital Humanities im deutschsprachigen (DHd)

:Raum

سوف تعقد هذه الجمعية مؤتمرها السنوي السـادس حول آليات ومكونات التاريخ الرقمي تحت شعار " الوسائط المتعددة ومتعدد الوسائط" "multimedia \& multimodal"( باللغة

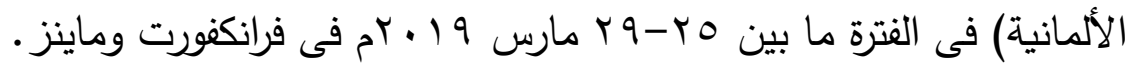

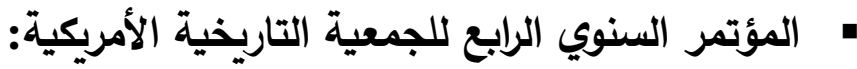

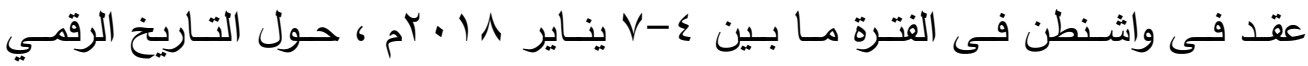
Getting Started In Digital History 2018 ، وسمح هذا الاجتماع للمشاركين بتعلم مهارات تقنية جديدة ذات علاقة بالتاريخ الرقمي ، وضم جلسات عن القصص الرقمية والمشاريع 
الرقمية، وورش عمل عن توظيف الأساليب والأدوات الرقمية وخاصةً أدوات التاريخ الرقمي فى التى

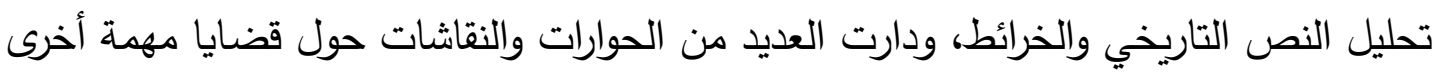

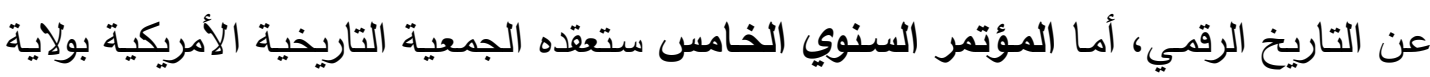

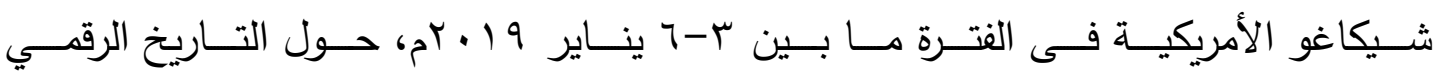

.Getting Started In Digital History 2019

\section{المحور الثاني : الفهم التاريخي: - (الثي}

تعريف الفهم النار بيفي:

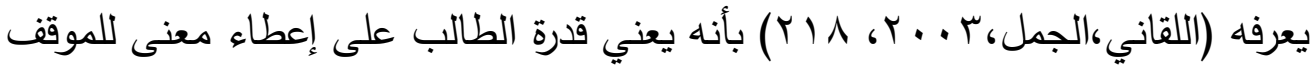
الذى يواجهه، ويستدل عليه من مجموعة السلوكيات العقلية التى يظهرها المتعلم، وتفوق مستوى

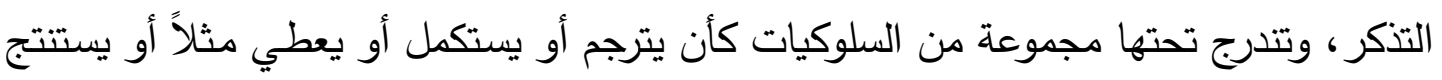
أو يعبر عن شئ ما.

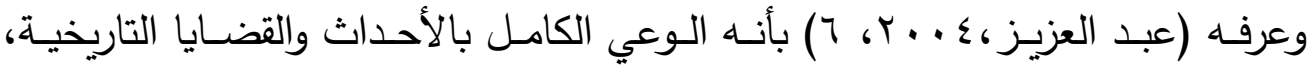
وتثمل قدرة الطالب على تفسير الأحداث، ربط الأحداث التاريخية بالماضي، باءئ تحليل الأحداث التاريخية إلى اسبابها الحقيقية، استتاج النتائج المترتبة على الألى الأحداث.

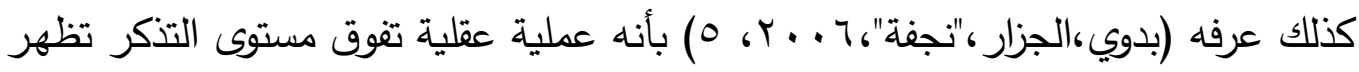

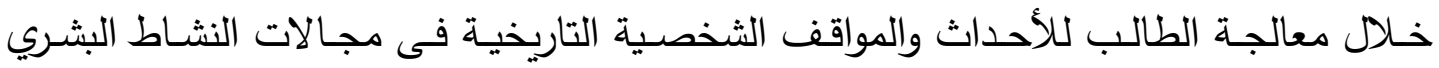

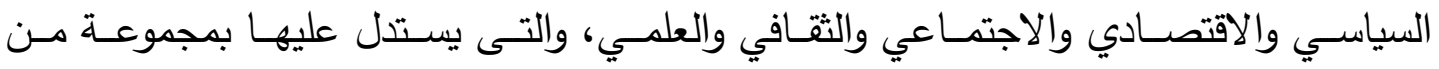

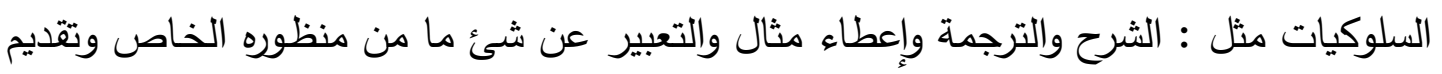

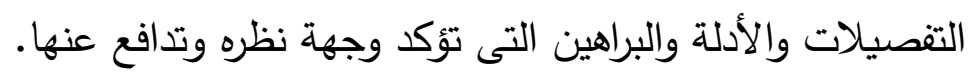

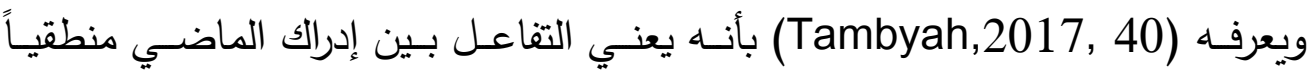

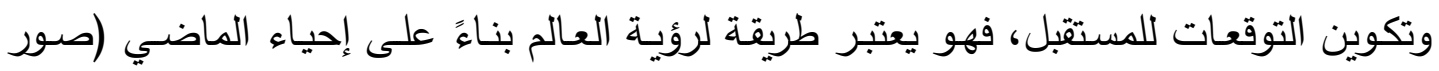

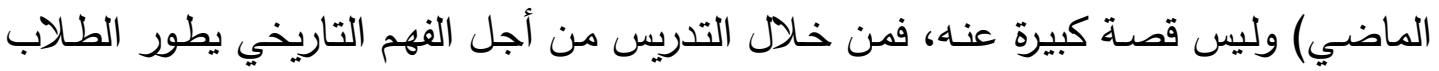
فهم ارتباطي للماضي يساعدهم على فهم الحاضر وتخيل المستقبل.

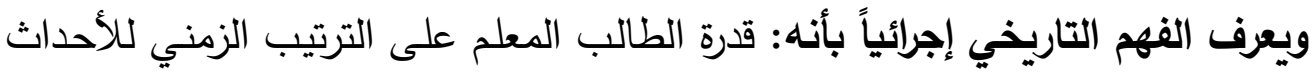

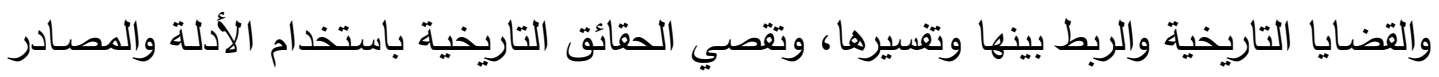

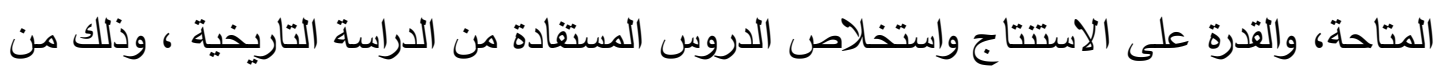


خلال معايثـة الموقف أو القضـية التاريخية وتحليلها وفهم مغزاهـا التاريخي، وتخيل المواقف والأحداث التاريخية ، والتفكير فى كيفية حدوثها من خلال استخدام التاريخ الرقمي.

أهمبة الفهم الناربنفي:

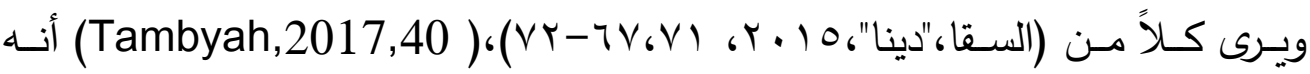

تتمثل أهمية الفهم التاريخي فما يلي:

يمثل هدفاً من أهم الأهداف التى تسعى دراسة مادة التاريخ إلى تحقيقها. • يعمل على ترتيب الأحداث التاريخية وعرضها فى تسلسل زمني واضح. • ينمي مفهوم الزمن والاستمرارية والتغير فى المجتمع. - يساعد المربين والمهتمين بتدريس التاريخ على تدريب المتعلمين على المهارات العقلية العليا البعيدة عن التلقين والحشو لعقولهم. " يساعد على بناء شخصية الأمة من خلال الفهم الصحيح للأحداث التاريخية. • يساعد على فهم الحاضر والتتبؤ بالمستقبل. يسـاعد على بنـاء الشخصية المنفتحة القادرة على النقد وإصدار الأحكام، وتقبل الرأى والرأى الآخر فى ضوء تقديم أسانيد وأدلة تاريخية. وفى هذا السياق استهدفت دراسـة روبينسون (Robinson,2002) التعرف على أثر تدريب الطلاب المعلمين بالمرحلة الأساسية قبل الخدمة على مهارات الفهم التاريخي من خلال مقرر طرق التدريس ، وتوصلت إلى أن هنالك تحسن ملحوظ فى الأداء التدريسي للعينـة بعد تتمية مهارات الفهم التاريخي لديهم وخاصـةً مـع استخدام المصـادر الأولية والوثائق التاريخية

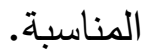

وكذلك أكدت دراسـة ديـا(Dia,2012) على أهميـة تعلم وتتميـة الفهم التاريخي لدى

الطلاب المعلمين، وأوصت بضرورة تضمينه فى برامج الإعداد وتدريبهم على هذه المهارات بشكل مقصود.

وأوصت دراسة (Ercik,Seixas,2015) بضرورة وأهمية وضـع عدد من المعايير المحددة

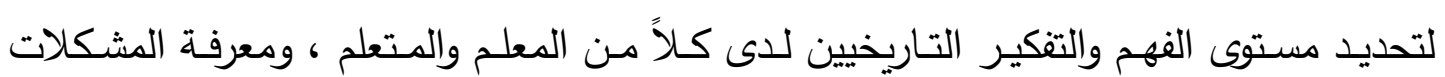
والعقبات التى تواجه المعلم فى تتمية الفهم والتفكير التاريخي لدى طلابه. 


\section{مهارات الفهم التناريخي:}

بعد اطلاع الباحثة على العديد من الدراسات والأبحاث التى تتاولت الفهم التاريخي

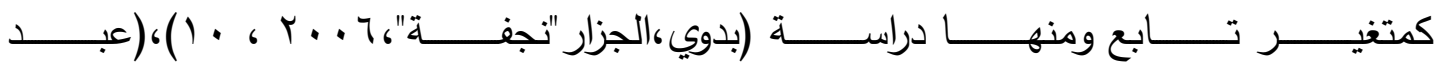

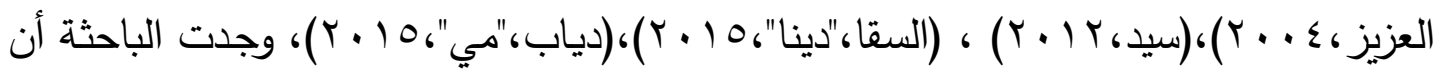

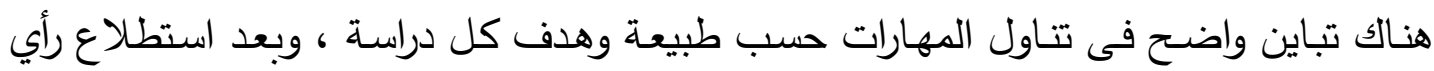

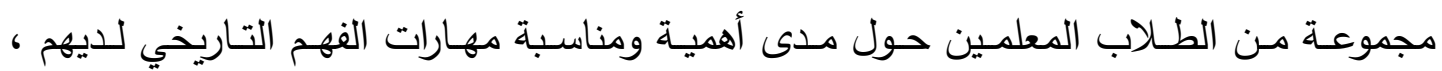

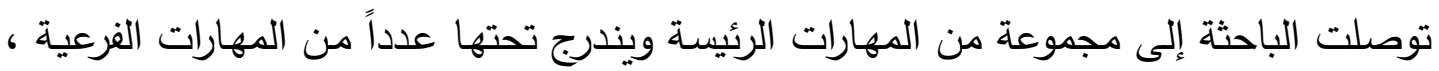

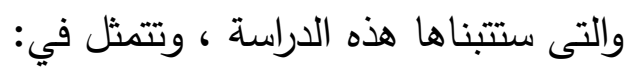

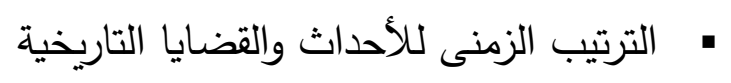

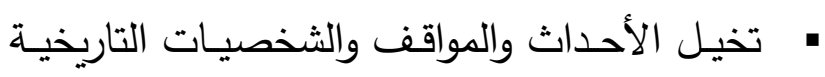
• تقصى الحقائق التاريخية باستخدام المصادر والأدلة التاريخية

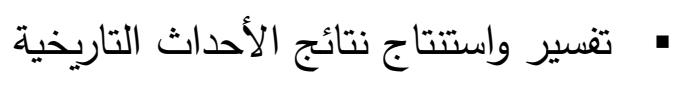
• استخلاص الدروس المستفادة من الدراسة التاريخية

التاريخ الرقمير وتنـمية الفهم التناريفي:

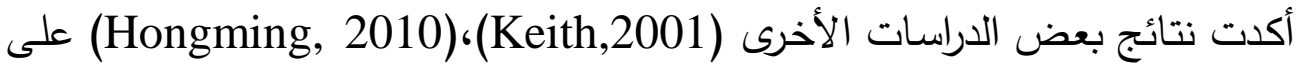
وجود العديد من التحديات التى تواجه الطلاب المعلمين فى مادة الدراسات الاجتماعية والتاريخ والتى تتمثل فى مدى تمكنهم من استخدام المصادر التاريخية والتطبيقات التكنولوجية الرقمية

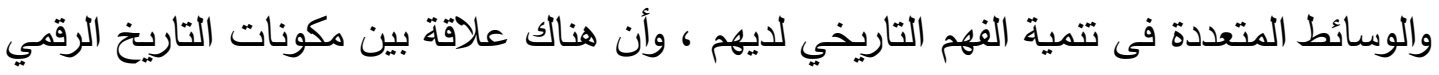
وتتمية الفهم التاريخي لاى الطلاب. ولذا أوصت نتائج بعض الدراسات مثل (Robinson,2002)، (Dia,2012) بضرورة

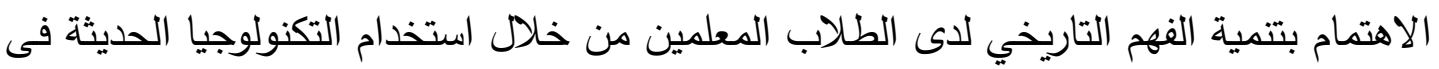

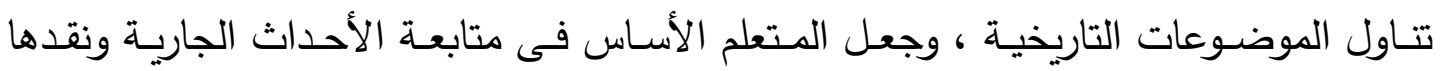

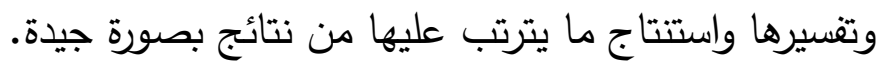
واستهدفت دراسـة ليو (Liaw,2010) الدمج بين التكنولوجيا الرقمية وتدريس التاريخ باستخدام استراتيجيات التعلم البنائي، وتوصلت إلى وجود معوقات تمنع دمج التكنولوجيا الرقمية

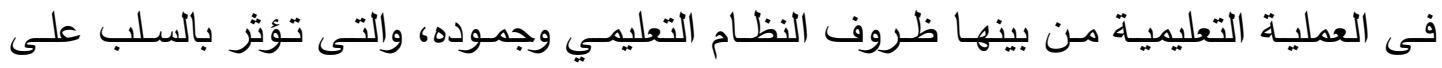


الطلاب المعلمين تجاه دمج التكنولوجيا فى الممارسات الصفية، وأوصت بضرورة تخطي هذه العقبات لتحقيق الدمج بصورة صحيحة فى تدريس التاريخ.

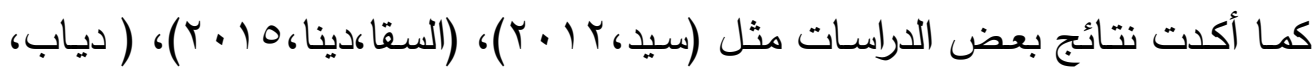

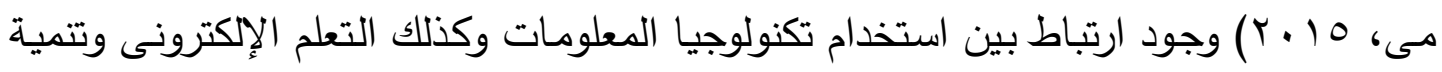
الفهم التاريخي فى المراحل التعليمية المختلفة. وأشار كل من(Calandra,Lee,2005,325) إلى أن التاريخ الرقمي يسهـ فى فهم

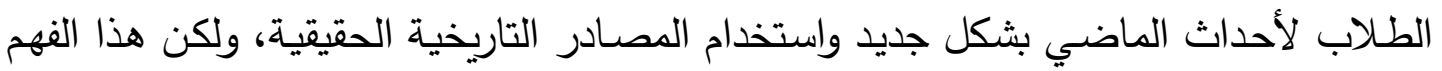

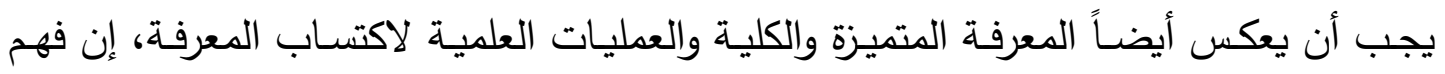
الطلاب للتاريخ أو الماضي يجب أن يكون فى شكل تفسيرات جديدة أو مبتكرة ، وهذا الفهم

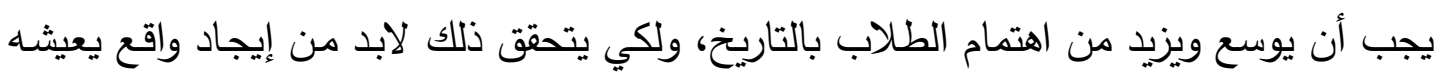

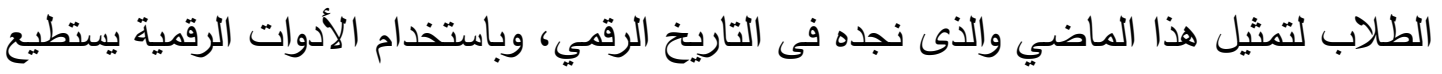

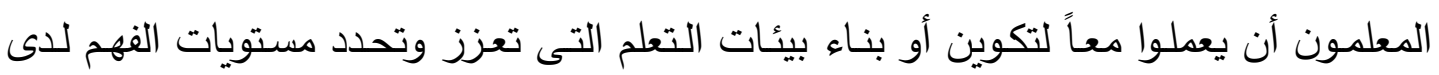
المتعلمين خاصة النشطين منهم. ولتأكيد العلاقة بين التاريخ الرقمي والفهم التاريخي يذكر (Lee,2014,144) أنه كان

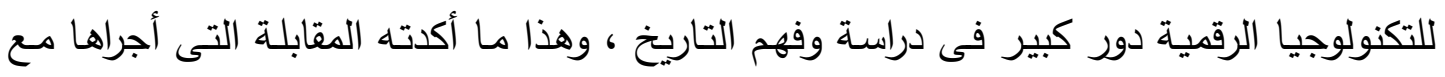

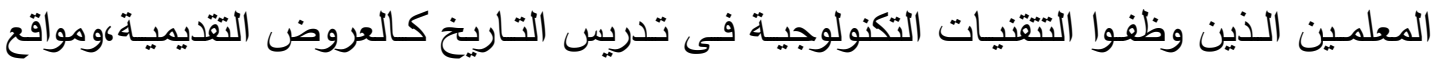

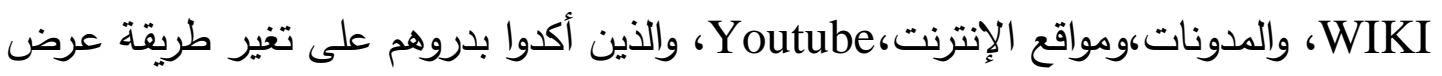

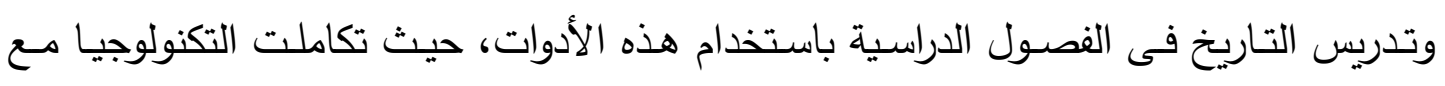

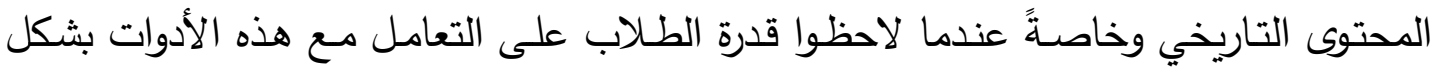

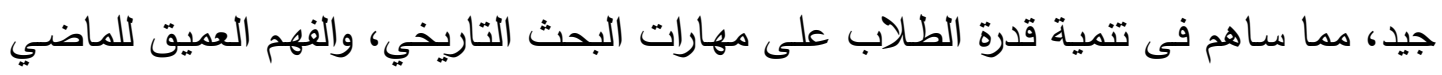
وأحداثه.

وفى هذا السياق أشـار (Rosinbum,2016) فى مقاله أن التاريخ الرقمي ظهر فى في

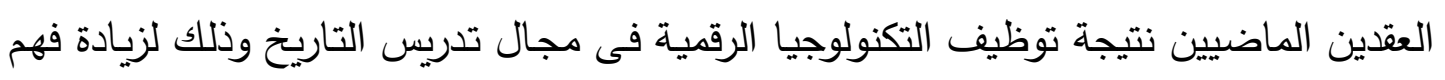

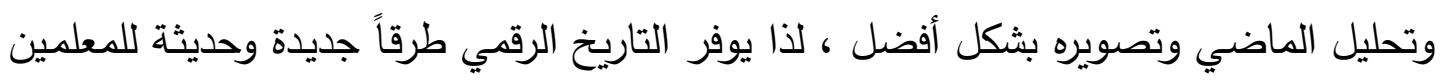

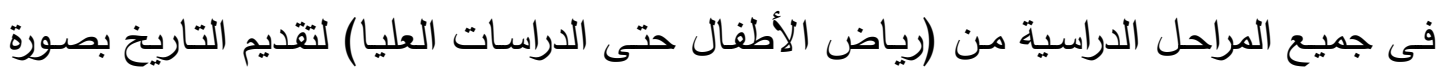

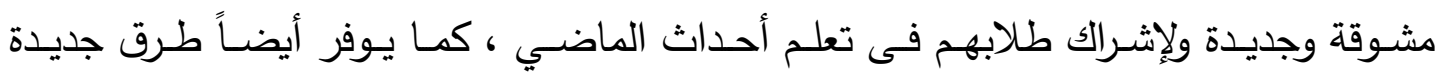

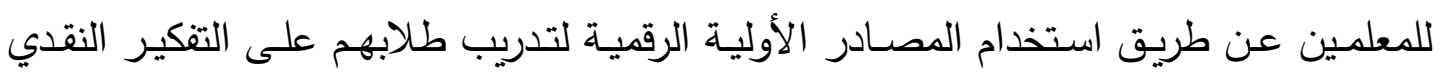


والتقسير ، ويرى أن التاريخ الرقمي يمكن أن يكسب الطلاب بجانب ذلك مهارات القرن الحادي

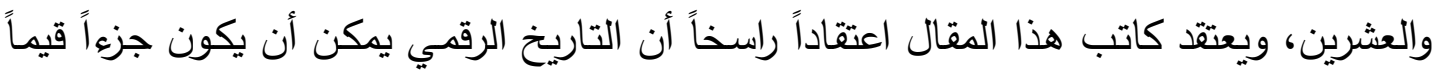
من تعليم التاريخ.

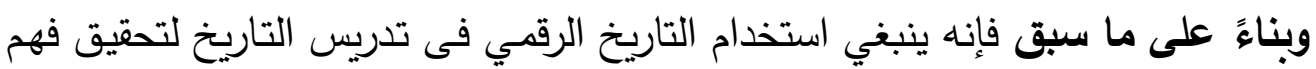

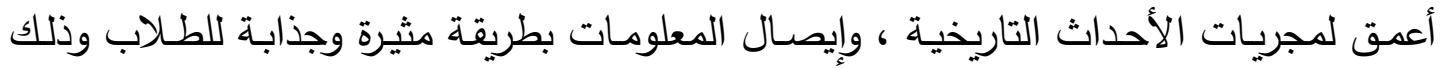
للاستفادة من المعلومات التاريخية فى تحقيق الأهداف المنشودة ، حيث أن استخدام التكنولوجيا

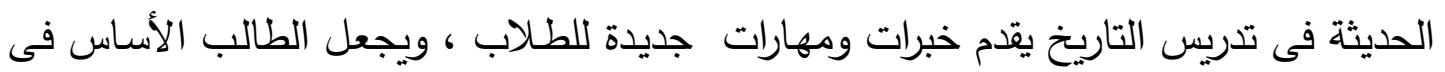

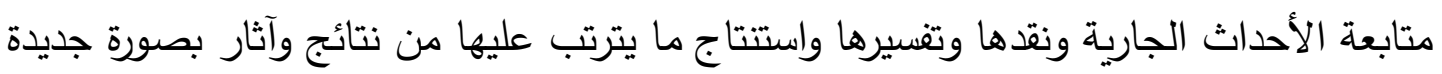

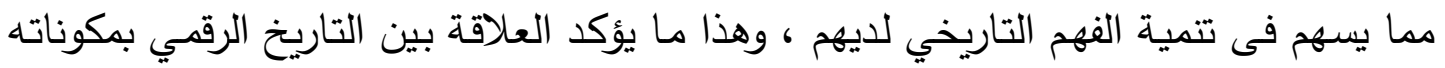

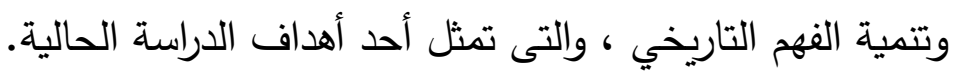
ولذا فمن المتوقع أنه يمكن للتاريخ الرقمي أن ينمي الفهم التاريخي من خلال:

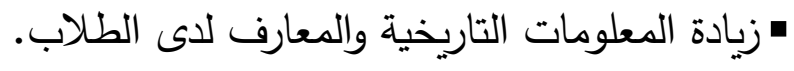
• تفسير الأحداث التاريخية بطريقة غير مألوفة. • التغلب على البعد الزماني والمكاني. • تخيل الأحداث والمواقف والثخصيـات التاريخيـة من خلال البيئات الإفتراضية والوسائل

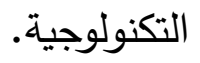
• تقصى الحقائق التاريخية باستخدام الدصادر والأدلة التاريخية الرقمية المتاحة.

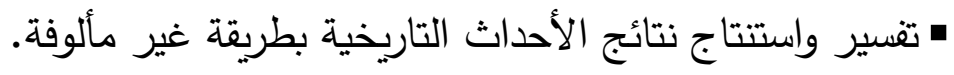

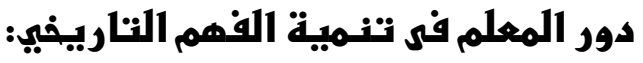

على معلم التاريخ أو الطالب المعلم أن يمتلك مجموعـة مـن الأداءات أو المهارات

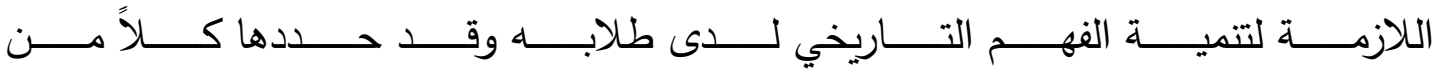

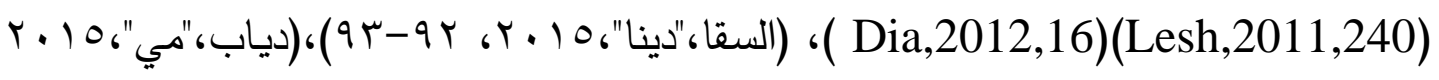

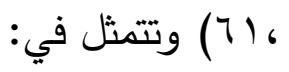
• الإلمام بالاتجاهات الحديثة فى مجال التخصص.

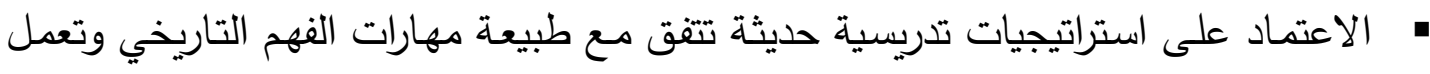
على تتميتها، والوصول إلى الحقائق التاريخية.

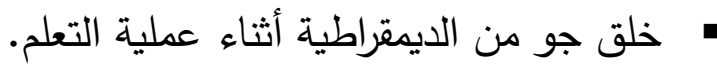
مساعدة الطلاب على اكتثاف وتحديد الفهم الخاطئ للأحداث التاريخية، ونقد مادة التعلم. 
• إثراك المتعمين فى العملية التعليمية وأن يكون دورهم أكثر إيجابية وفاعلية.

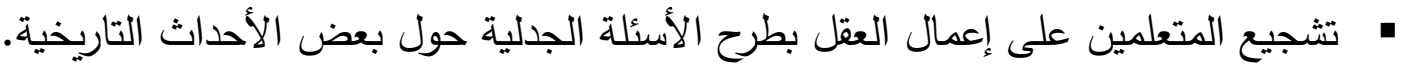
• توظيف التكنولوجيا الحديثة، وفهم دورها في التطوير والتحسين والتتمية.

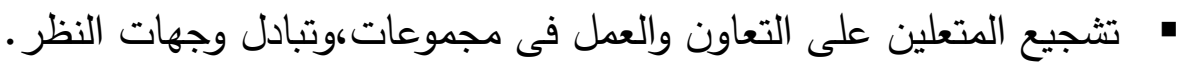

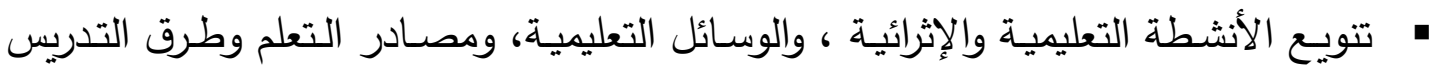

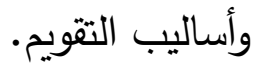

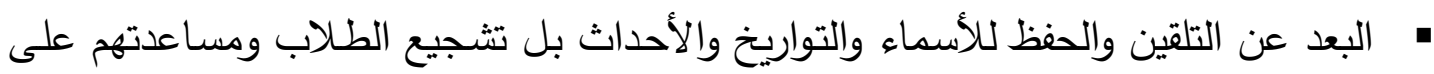
جمع المعلومات التاريخية بأنفسهم.

ثامناً: الجانب التطبيقي للبدث، ويتضمن: إعداد أدوات البحث، والتى اشتملت على:

1- إعداد قائمة مهارات الفهم التاريخكى المناسبة للطلاب المعلميز ،وتم ذلك من خلال: أ) تحديد الهدف من القائمة ، ومصادر الشتقاقها من خلال الرجوع إلى العديد من المصادر

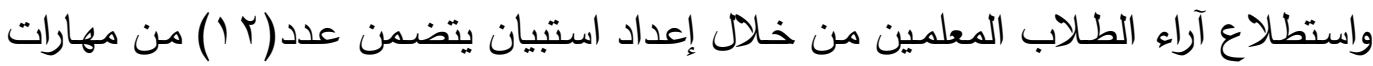

الفهم التاريخي تم تطبيقه على عينة من الطلاب المعلمين بالفرقة الثالثة (شعبة التاريخ)

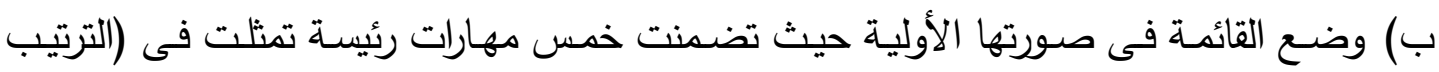
الزمنى للأحداث والقضــايا التاريخيـة- تخيـل الأحـداث والمواقـف والثخصيـات التاريخيـة تقصى الحقائق التاريخية باستخدام الدصادر والأدلة التاريخية - تفسير واستتاج نتائج الأحداث التاريخية - استخلاص الدروس المستفادة من الدراسة التاريخية)، ويندرج تحت كل مهارة عدد من المهارات الفرعية المرتبطة بها ، وتم صياغتها فى صورة إجرائية قابلة للتقويخ. ج) ضبـطـ القائعــة ووضعها فى صـورتها النهائيـة بعد الانتهاء من إجراء التعديلات التى التى أشار إليها السادة المحكون، وأصبحت تشتمل على خمس مهارات رئيسة يندرج تحتها عدد إنداء

$$
\text { من المهارات الفرعية وعددها (rT). }
$$

\section{ץ- إعداد اختبار الفهم التاريخى، من خلال :}

تحديد هدف الاختبار وحدوده، ومفرداتـه التى بلغت (ع) مفردة، وكذلك تعليمات الاختبار ، وكذلك إجراء التجربة الإستطلاعية للاختبار على عينة استطلاعية بلغ عددها (· (†)

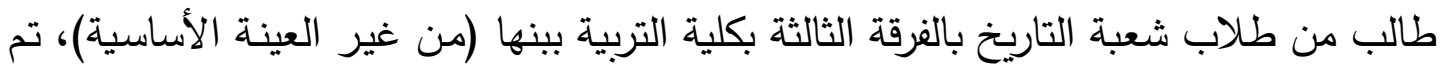
حساب ثبات الاختبار بتطبيق هذه معادلة بيرسون وجد أن قيمة معامل الثبات للاختبار هى لالئ 


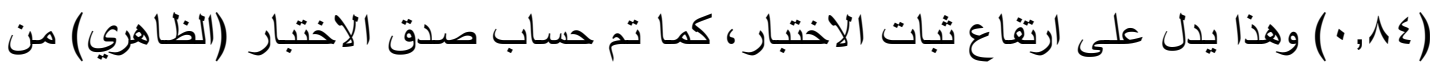

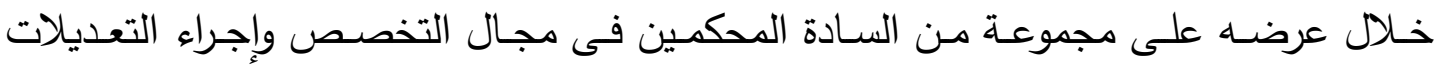

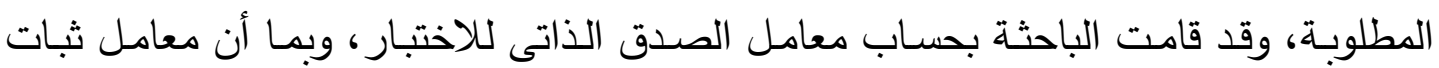

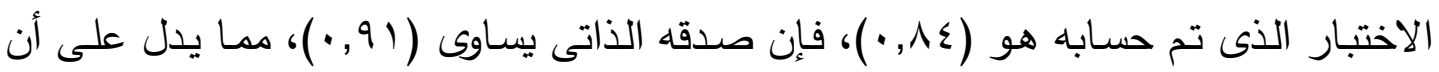

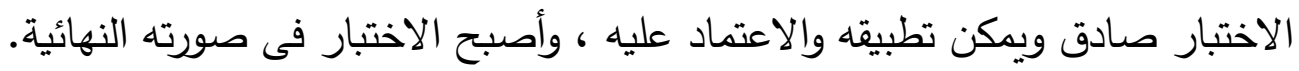

"م- - إعداد البرنـامج القائم على التناريخ الرقهي لتنميـة الفهم التاريفي لدى الطلاب المعلمين:

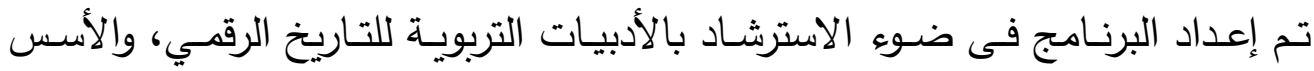

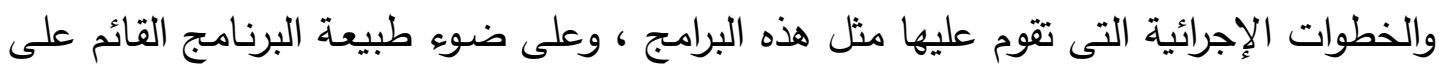
التاريخ الرقمي تم مراعاة الأسس الآتية:

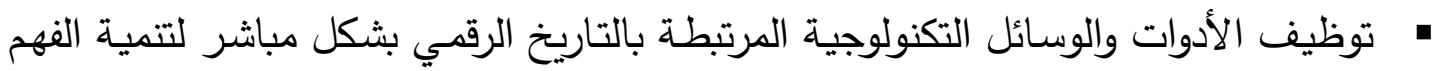

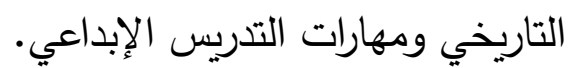

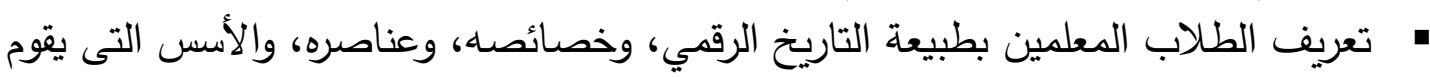

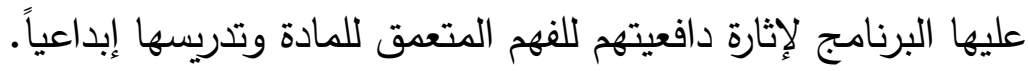

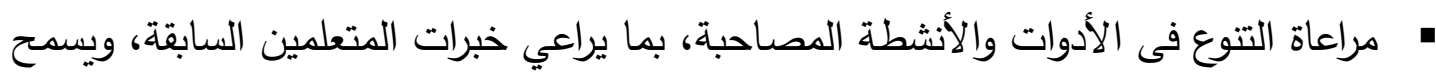

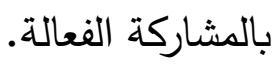
مراعاة أن تكون الأدوات التكنولوجية والأنشطة المصاحبة لها مرتبطة بحاجات وخصائص

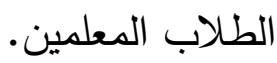

ولقد استعانت الباحثة بالنموذج الأجنبي(Lessons Using Digital History)

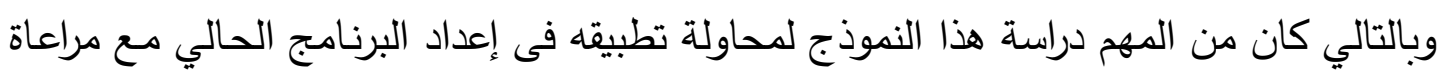

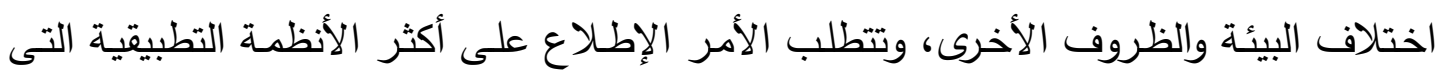

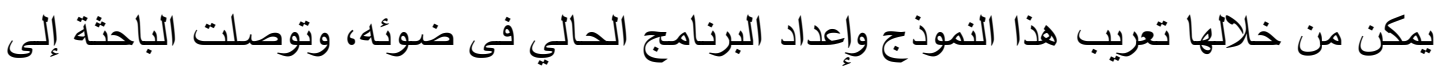

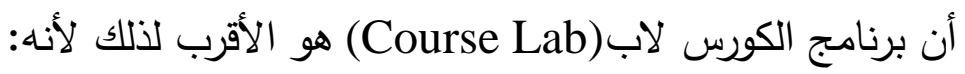
• • بعد أحد أنظمة تأليف المحتوى الرقمي. • يتفوق على الأنظمة الأخرى بقوته وسهولة استخدامه وتوافقه مع البيئة العربية. • يتم استخدامه لإنشاء بيئة تعلم تفاعلية عالية الجودة.

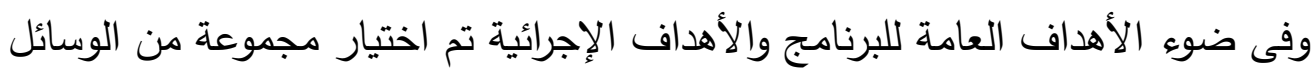
والمكونات الرقمية المناسبة لموضوعات التاريخ المختارة مثل ( المصـادر التاريخية الرقميـة- 
-WIKI الرقمية - مسارات الروابط التاريخية الرقمية - أمـاكن تاريخية ثلاثيـة الأبعاد - صور (ثابتة ومتحركة وقابلة للزووم) -Google Maps... وغيرهـا)، وتم التأكد من صـلاحية البرنـامج للتطبيق بعد تجريبه وعرضـه على مجموعـة من المتخصصين فى مجال تكنولوجيا التعليم وأصبح بذلك فى صورته النهائية.

\section{عرض النتائج وتدليلها إحصائياً وتفسيرهـا:}

لاختبار صحة الفرض الخاص بالمتغير التابع والذي ينص على أنه: "يوجد فرق دال إحصائياً عند مستوى دلالة (a 1 (a,05) بين متوسطي درجات الطلاب فى التطبيقين القبلي والبعدي فى اختبار الفهم التاريخي"، تم حساب قيمة (ت) T.test لالالة الفروق بين متوسطي

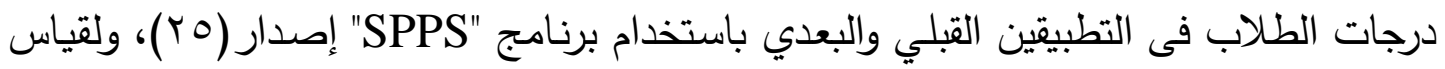

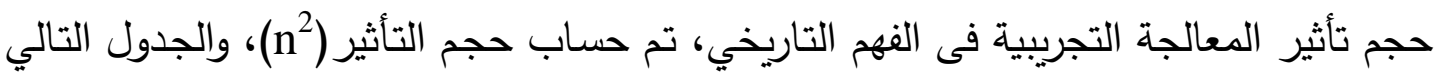
يوضح ذلك:

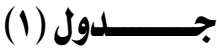

المتوسط والانحراف المعياري وقيمة (ت) لدلالة الفروق بين متوسطي

درجات الطلاب في التطبيقين القبلي والبعدي لاختبار الفهم التاريخي

\begin{tabular}{|c|c|c|c|c|c|c|c|}
\hline مقدار حجم التأثير & حجم الآثر & مستوى الدلالة & درجات الحرية & قيمة"ت" & الانحراف المعياري & المتوسط & التطبيق \\
\hline \multirow{2}{*}{ كبير } & \multirow{2}{*}{$\cdot, 97$} & \multirow{2}{*}{$\cdot, \cdot 0$} & \multirow{2}{*}{ Tr } & \multirow{2}{*}{$r q, r$} & $\vee, \wedge Y$ & $r v, \wedge q$ & القبلي \\
\hline & & & & & $\Lambda, \cdot 1$ & $\Delta r, \wedge \Delta$ & البعدي \\
\hline
\end{tabular}

يتضح من الجدول السابق ما يلي:

" وجود فرق ذو دلالمة إحصـائية عند مستوى(0. .. ·) بين متوسط درجات التطبيق القبلي ومتوسط درجات التطبيق البعدي لاختبار الفهم التاريخي لصالح التطبيق البعدي، مها يدل

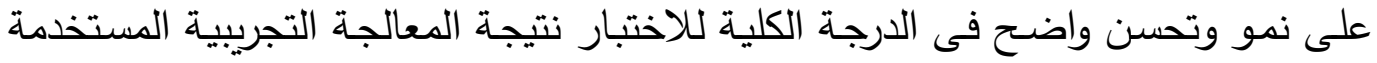

$$
\text { (البرنامج القائم على التاريخ الرقمي). }
$$

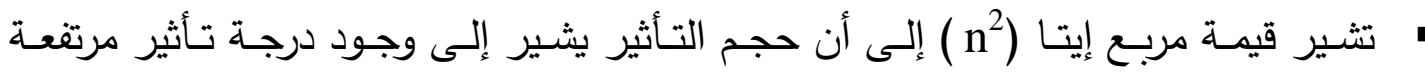
للمعالجة التجريبية الدستخدمة (البرنـامج القائم على التاريخ الرقمي) على الدرجـة الكلية

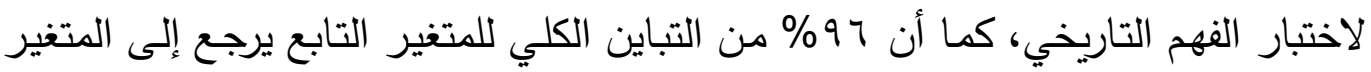


المستقل، مما يدل على وجود تأُير كبير للمعالجة التجريبية المستخدمة فى تتمية مهارات

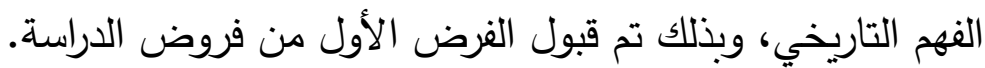

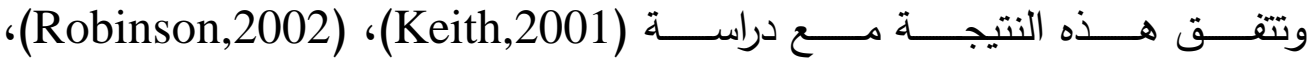

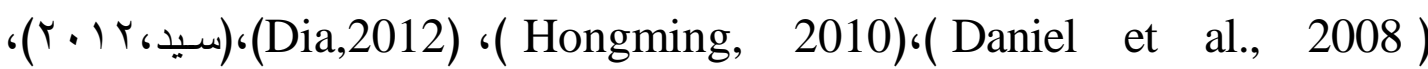

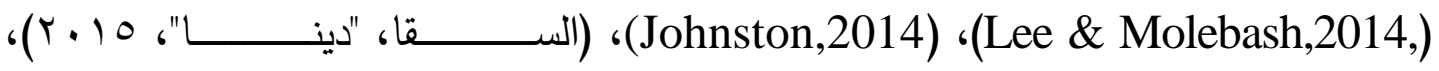

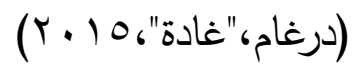

\section{ويمكن تفسير تلك النتيجة على النحو التالي:}

استخدام التكنولوجيا الحديثة فى تتـاول الموضـوعات التاريخية، وإعـادة صـياغة وتنظيم

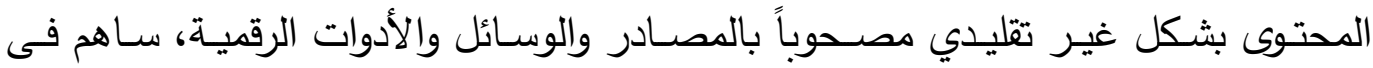
تحسن فهم الطلاب للحقائق والمعلومات التاريخية. البرنامج يقوم على مجموعة من المكونات والوسائل الرقمية المتضمنة الأنشطة الإثرائية المتنوعة التى تتيح للطلاب فرص المشاركة معاً، ومن خلال المناقثات والحوارات التبادلية التى تحثهم على التفكير والفهم، والبحث عن المعلومـات من مصـادرها المختلفة، وهذا بالطبع ينمي فهم الطلاب للمعلومات والحقائق التاريخية. إن التاريخ الرقمي مجال حديث متطور يسمح باستخدام أحدث التقنيات ليس فقط لتفسير أو شرح الأحداث التاريخية فى الماضي، وإنما لإحيائه بثكل جديد مختلف، وبذلك يدعم تغيير تعلم وتعليم التاريخ فى الواقع التعليمي، ويحفز الطلاب على التعلم النثط وتحقيق تعلم

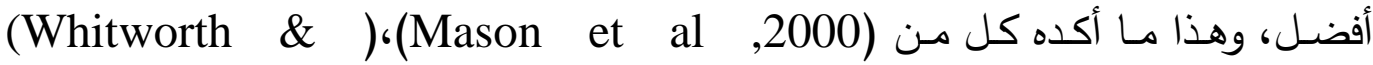
(Johnston,2014) (Lee \& Molebash,2004)،Berson,2003 البرنامج بما يتضمنه من وسائل وأدوات تكنولوجية أدى إلى إثارة دافعية الطلاب، ومنحهم خبرة تعلم أكاديميـة قويـة من خـلال السماح لهم بالتجول والتتقل عبر المواقـع التاريخية الإلكترونية، وبطريقة منظمة، ومنحهم معلومات أكثر عن الأحداث والقضايا التاريخية. ركزت الأسئلة التقويمية التى تضمنها البرنامج على طرح أسئلة يتطلب حلها الاستتتاج ونقد وتحليل وتفسير الأحداث والقضايا التاريخية ومحاولة ترتيبها زمنياً، وربط الأسباب بالنتائج، وتقصي الحقائق التاريخية للوصول إلى نتائج جديدة، وتخيل الأحداث التاريخية فى الماضي 
ومعايثـته مـن خـلال الأفـلام، والفيديوهات، والصـور المصـاحبة، كل هذا أعطى فرصــة للطلاب للتدريب وممارسة ما يتطلبه الفهم التاريخي، مما أدى إلى تنميته لديهم.

تاسعاً: التوصيات والمقترحات:

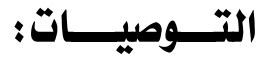

فى ضوء ما أسفرت عنه النتائج يوصي البحث بما يلي:

ا - إعـادة تخطيط برامج إعداد معلم التاريخ -قبـل الخدمـة- بكليـة التربية بحيث تتضـمن

مكونات التكنولوجيا الرقمية الحديثة والمناسبة منها.

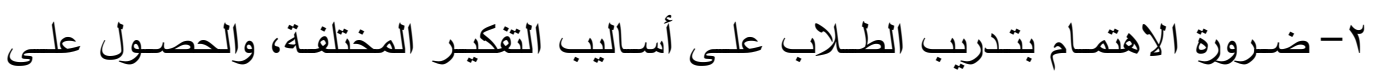
المعلومات التاريخية من مصـادر متعددة، وإعادة تتظيمها والتحقق منها وتفسيرها وفهم طبيعة الأحداث التاريخية. ب- الاهتمام بالتاريخ الرقمي ومـا يرتبط بـه من أدوات ووسـائل تكنولوجية حديثة، وأنشطة تعليم وتعلم مناسبة، وأساليب تقويم فى سياق التعليم الجامعي. ع - الاهتمام بتدريب معلمي التاريخ - أثناء الخدمة- على استخدام التكنولوجيا الحديثة فى مجال تدريس التاريخ.

يقترح البحث الحالي ما يلي:

إعداد برنامج تدريبي للمعلمين - أثناء الخدمة - لتدريبهم على استخدام التاريخ الرقمي فى تدريس التاريخ.

فاعلية استخدام التاريخ الرقمي فى سياق تتمية الفهم التاريخ لدى الطلاب فى مراحل

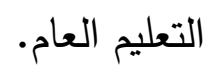

إجـراء دراسـات حـول فاعليـة بـرامج قائمـة على التـاريخ الرقمـي فـى تتميـة متغيـرات

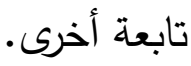




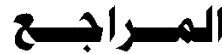

\section{أولاء المراجســــ العربيــــة:}

بدوى، عاطف محمد (T + . ץ). علم التاريخ، جدواه ووظائفه التتربوية فى عالهنا المتغير بين التنظير والتطبيق. القاهرة: عالم الكتب.

بدوي،عاطف محمد،الجزار كنجفة قطب( ( . . ץ): فعالية استراتيجية التساؤل الذاتي فى تدريس التاريخ على تتمية الفهم التاريخي ومهارات ما وراء المعرفة لدى طلاب الصف الأول الثانوي، مجلة الجمعية التربوية للدراسات الإجتماعية، ع(؟)، كلية التربية، جامعة عين شمس.

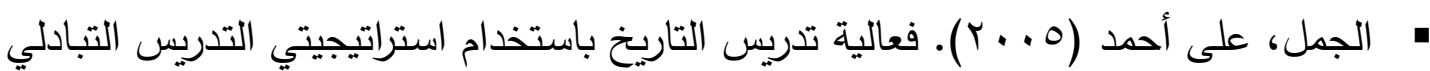

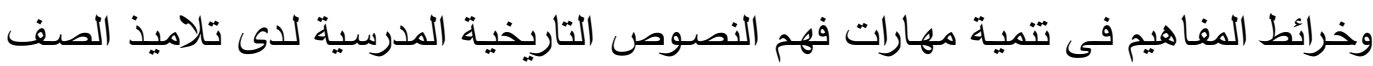

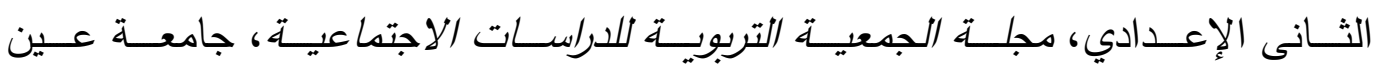

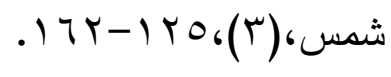

درغام، غادة عويس عويس على(10 + ب): برنامج مقترح قائم على التكنولوجيا الرقميـة فى الدراسات الاجتماعية لتتمية مهارات التتكير التاريخي ومهارات الاتصال الاجتماعي لاى تلاميذ الصف الثالث الإعدادي، رسالة دكتورة غير منشورة، كلية التربية، جامعة عين شمس. دياب، مى كمال موسى (10 + ب). أثر استخدام استراتيجية الرحلات المعرفية عبر الويب فى تتمية مهارات الفهم التاريخي لدى طلبة المرحلة الثانويـة، رسالة دكتوراة غير منشورة،

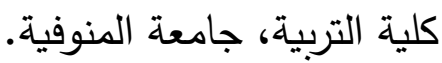
السقا، دينا سعيد سيد (10 + †): موديول رقمي مقترح لتنمية الفهم التاريخي والاتجاه نحو التعلم الرقمي لدى تلاميذ المرحلة الإعدادية، رسالة ماجستير ، كلية التربية، جامعة طنطا. سيد، محمد على حسين (Y Y (Y). فعالية وحدة قائمة على التعلم الإكترونى فى تتمية الفهم التاريخي لدى تلاميذ المرحلة الإعدادية لمادة الدراسات الاجتماعية، رسالة ماجستير غير منشورة، كلية التربية، جامعة حلوان. 


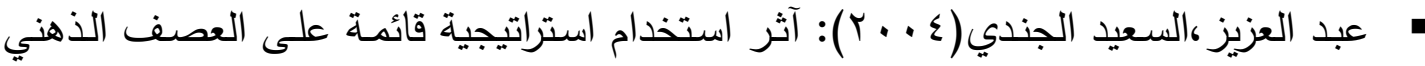
فى تدريس التاريخ على الفهم التاريخي وتنمية التفكير الإبداعي لدى طلاب الصف الأول الثانوي، مجلة كلية التربية ببنها،أكتوبر، ع(هو).

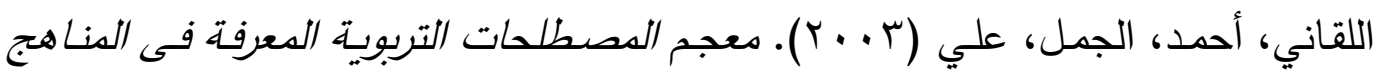
وطرق التدريس. طم ، القاهرة: عالم الكتب.

\section{ثانياً : المراجع الأجنبية :}

- Calandra ,B.,Lee,J.(2005): The digital history and pedagogy project : Creating an interpretative / pedagogical historical website, The Internet and Higher Education , ELSEVIER,8,pp323-333.

- Clarke ,W., Lee, J.,(2004) : The promise of digital history in the teaching of local history, The Clearing House , 78(2), 84-87

- Daniel J,. Frisch, M,. Gallagher, P,. Mintz, S,. Sward, K,. Taylor ,A,. Thomas III,W,., \& Turkel,W,. (2008). Interchange: The promise of digital history. Journal of American History, 95(2) ,452-491.

- Dia,R,.(2012).Program and Practices: Student's historical understanding, reflection and learning in international baccalaureate, Advanced Placement and Regular World History Courses , PH.D, university of Nebraska -Lincoln.

- Ercik,K.,Seixas,P.,(2015): Issues in Designing Assessment of Historical Thinking, theory into Practice, Vol 54,issue3,pp 255-262.

- Ewing,T,E.(2009):Practicing digital history at the intersection of teaching ,research,and outreach,intersections,AHAperspectives on history, $47(5)$. 
- Friedman, A.M., Hicks, D. (2006). The state of the field: Technology, social studies, \& teacher education. A "concise discussion" on a sprawling and evolving field,Contemporary Issues in Technology and Teacher Education, 6(2), 246-258.

- Hongming, L.(2010). Using online primary source resources in fostering historical thinking skills: The Pre-service social studies teacher's understanding, PH.D, The University of Texas at Austin.

- Johnston,R., (2014): History in your hand: A case study of digital history and augmented reality using mound 72, Master of Arts, Southern Illinois University Edwardsville, Proquest.

- Keith,Barton(2001):you'd wanting to know about the past : Social context of children's historical understanding in northen Ireland and U.S.A comparative education, Vol37.

- Lee, J.,, Molebash, P.(2004). using digital history for positive change in social studies education. Journal Of Computing in Teacher Education, 20(4), 153-157.

- Lee,J,K.Molebash,P(2014): Using personal digital histories to engage teachers in contemporary understandings of teaching social studies, The Journal Of Social Studies Research ,38,159-172.

- Lee,J.,Gorman,L(2014): Effecting learning for Historical understanding ,Doctoral Education,Proquest,Northeastern Universty,Massachusetts.

- Lee,J.K.(2002):Digital history in the history / social studies classroom.The History teacher,35(4),503-518.

- -Lesh ,Bruce.,(2011): Who Won't you Just Tell Us The Answer? Teaching Historical Thinking In Grades 7-12, Stenhose.Publish Protland 
- Liaw,H.,(2010):Using Online Primary Source Resource In Fostering Understanding , Doctoral Of Philosophy, University Of Texas,Austin,Texas.

- Robinson, Cecil D. (2002). Using documents for historical uunderstanding: A stay of preservice elementary social studies methods class, PH.D, dissertation, University of Colorado at Boulder, AAT 3043559.

- Rosinbum,John(2016):Teaching with \#DIGHIST(Digital History):Introducing a new series on using digital projects in the classroom, The News Magazine Of The American Historical Association, V54,Issue 5A. Available on: www.historians.org.

- Tambyan, Mallihai, M (2017): Teaching for 'Historical understanding': What knowledge(s) do teachers need to teach history?, Australian Journal Of Teacher Education,42(5).

- Zahavi, G., (2014):Notes from the field : Digital history and Oral history , In Boyd ,d et al. ,(eds)(2014) : Oral History and Digital Humanities, Palgrave Macmillan ,USA. 